\title{
Sonic Hedgehog signaling pathway in gynecological and genitourinary cancer (Review)
}

\author{
ANNA KOTULAK-CHRZĄSZCZ, ZBIGNIEW KMIEĆ and PIOTR M. WIERZBICKI \\ Department of Histology, Faculty of Medicine, Medical University of Gdansk, 80211 Gdansk, Poland
}

Received July 29, 2020; Accepted March 10, 2021

DOI: $10.3892 / \mathrm{ijmm} .2021 .4939$

\begin{abstract}
Cancers of the urinary tract, as well as those of the female and male reproductive systems, account for a large percentage of malignancies worldwide. Mortality is frequently affected by late diagnosis or therapeutic difficulties. The Sonic Hedgehog ( $\mathrm{SHH})$ pathway is an evolutionary conserved molecular cascade, which is mainly associated with the development of the central nervous system in fetal life. The present review aimed to provide an in-depth summary of the SHH signaling pathway, including the characterization of its major components, the mechanism of its upstream regulation and non-canonical activation, as well as its interactions with other cellular pathways. In addition, the three possible mechanisms of the cellular SHH cascade in cancer tissue are discussed. The aim of the present review was to summarize significant findings with regards to the expression of the $\mathrm{SHH}$ pathway components in kidney, bladder, ovarian, cervical and prostate cancer. Reports associated with common deficits and de-regulations of the SHH pathway were summarized, despite the differences in molecular and histological patterns among these malignancies. However, currently, neither are $\mathrm{SHH}$ pathway elements included in panels of prognostic/therapeutic molecular patterns in any of the discussed cancers, nor have the drugs targeting SMO or GLIs been approved for therapy. The findings of the present review may support future studies on the treatment of and/or molecular targets for gynecological and genitourinary cancers.
\end{abstract}

\section{Contents}

1. Introduction

2. Mammalian Sonic Hedgehog canonical pathway

Correspondence to: Dr Piotr M. Wierzbicki, Department of Histology, Faculty of Medicine, Medical University of Gdansk, ul. Debinki 1, 80211 Gdansk, Poland

E-mail: piotr.wierzbicki@gumed.edu.pl

Key words: bladder cancer, cervical cancer, drug resistance, GLI family zinc finger, kidney cancer, microRNA, ovarian cancer, prostate cancer, patched 1 , Sonic Hedgehog, smoothened, frizzled class receptor
3. Role of microRNAs (miRNAs/miRs) in upstream $\mathrm{SHH}$ gene regulation

4. Activation of the target genes of the SHH pathway via GLI factors and crosstalk with other cellular pathways

5. Non-canonical, GLI-independent activation of $\mathrm{SHH}$ signaling

6. SHH signaling in cancer cells and its implications for the tumor microenvironment

7. Sonic Hedgehog signaling in cancers of the urinary tract

8. SHH pathway in gynecological cancers

9. SHH pathway in cancers of the male reproductive system

10. Conclusions and future perspectives

\section{Introduction}

Genitourinary and gynecological cancers are a wide group of cancers with differences in etiology, rapidity of progression and treatment strategies (1-7). Among these, prostate and cervical cancers (CCs) are associated with high incidence and mortality rates worldwide (8). The common feature of the majority of defined tumors is a lack of characteristic symptoms in the early stages, which often leads to a diagnosis of invasive or metastatic disease and treatment difficulties $(1,3,9,10)$. Therefore, novel prognostic and predictive clinical and molecular targets for modern drugs are required to improve the therapeutic process.

The Sonic Hedgehog (SHH) signaling pathway is an evolutionary conserved molecular cascade discovered by Nusslein-Volhard and Wieschaus during their studies on D. melanogaster body segmentation (11). Further research has revealed that this signaling plays an important role in human embryonic development, as well as in maintaining the homeostasis of organisms in postnatal life (12-14). The canonical signaling pathway includes several proteins involved in signal transmission from the cell membrane to the nucleus (Fig. 1) (15). The activity of the pathway is regulated by the SHH signaling ligand, which can bind to patched 1 (PTCH1) receptor (16). This interaction results in the translocation of smoothened, frizzled class receptor (SMO) (17) from the cytoplasm to the cell membrane in the region of the primary cilium (18). The single non-motile cell protrusion can be found in almost all cell types. The core of the primary cilium is composed of nine microtubule doublets, without central microtubule pairs and dynein arms, which are found in the motile cilia (19). The ciliary localization of SMO promotes intracellular signal transmission 
to the cytoplasm, protein complex composed of SUFU negative regulator of hedgehog signaling (SUFU) protein and GLI family zinc finger 2 and 3 (GLI2/3) transcription factors (20). Consequently, SUFU undergoes proteolytic degradation and GLIs (the SHH pathway effectors) translocate to the cell nucleus and act as transcription factors for various target genes involved in cell survival (i.e., BCL2), proliferation [ cyclin D (CCND1) and MYC proto-oncogene, bHLH transcription factor $(M Y C)](15)$, epithelial-mesenchymal transition [snail family transcriptional repressor 1 (Snail)] and angiogenesis (vascular endothelial growth factor A), or genes that regulate $\mathrm{SHH}$ signaling, such as GLII (positive feedback loop) and PTCHI (negative feedback loop) (21). The upregulation of SHH pathway components and, particularly GLI transcription factors, is frequently associated with the progression of various types of cancer, including retinoblastoma, breast, colorectal and non-small cell lung cancer $(22,27)$, acute myeloid leukemia (AML), as well as basal cell carcinoma (BCC) $(28,29)$. Drugs that inhibit SMO have been introduced for BCC and AML and tested in other malignancies; however, since GLI activation may occur in an SMO-independent manner, drug resistance occurs frequently during treatment $(17,30)$. To date, no SHH pathway-targeted drugs have been introduced for the treatment of gynecological or genitourinary tract cancers, at least to the best of our knowledge. The present review includes a comprehensive description of SHH signaling components and their role as potential molecular targets, which may prove useful for the treatment of genitourinary and gynecological cancers. The present review also aimed to discuss the upstream regulation of the $\mathrm{SHH}$ pathway, as well as its correspondence with other cellular pathways, which may support the introduction of a combination of drugs targeting different tumor-related pathways.

\section{Mammalian Sonic Hedgehog canonical pathway}

Sonic hedgehog signaling molecule. SHH signaling transfers signals from the extracellular environment and activates the expression of genes involved in cell survival and proliferation (28). A schematic presentation of the pathway is shown in Fig. 1A and B, and the core elements of the pathway are briefly presented in Table I.

SHH signaling is triggered by the cell membrane binding of the functional SHH glycoprotein. It acts as a classic morphogen during embryonic development, where it is involved in the crucial phases, such as patterning of the ventral neural tube, the anterior-posterior limb axis and ventral somites (20). Germinal mutations of the $\mathrm{SHH}$ gene, located at 7q36.3, lead to congenital defects, such as holoprosencephaly (31-33). Recent research on genomic DNA of patients affected by holoprosencephaly has revealed that eight synonymous single-nucleotide variants in the SHH gene are associated with a reduced level of SHH protein (34). A recent in vivo study on Cre-modified mice demonstrated that $\mathrm{SHH}$ expression was also crucial for proper fetal development of the tongue and mandible (35). SHH is the most well-known among other hedgehog family proteins, comprising Desert Hedgehog (DHH) and Indian hedgehog ( $\mathrm{IHH})$ molecules (36). Although all hedgehog family members can bind to the PTCH1 receptor, their tissue distribution and roles are different $(20,37)$. It has been proven that SHH protein plays a significant role in central nervous system development (38). The activity of IHH in skeletal tissue formation has been reported, whereas DHH is present only in granulosa cells of ovaries and Sertoli cells of the testis $(20,32)$. Post-translational modifications of all three hedgehog protein family members are required for their attachment to the PTCH1 receptor (15). During this molecular process, the full-length $\mathrm{SHH}$ protein $(\sim 45 \mathrm{kDa})$ undergoes autoproteolysis and cleavage into the $\mathrm{C}-(\mathrm{C}-\mathrm{SHH} ; \sim 25 \mathrm{kDa})$ and $\mathrm{N}-(\mathrm{N}-\mathrm{SHH} ; \sim 19 \mathrm{kDa})$ terminal domains $(39,40)$. C-SHH is an auto-processing molecule that participates in the attachment of cholesterol to the C-terminal end of N-SHH. Furthermore, the $\mathrm{N}$-terminal end of N-SHH binds to palmitic acid moiety through the reaction induced by hedgehog acyltransferase (HHAT), which is necessary for its full biological activity $(41,42)$. The activity of HHAT may be blocked by the use of RU-SKI inhibitors (RU-SKI 41, 43, 101 and 201; not shown in the figures) (43); however, overall cytotoxicity was observed for RU-SKI 41, 43 and 101 in an in vitro study (44). Currently, there are no data available regarding the use of RU-SKI inhibitors in clinical studies, at least to the best of our knowledge. Finally, through its interaction with dispatched resistance-nodulation-division (RND) transporter family member 1 , modified $\mathrm{N}-\mathrm{SHH}$ is secreted to the extracellular matrix (ECM) and may act as a biologically active upstream regulator of the $\mathrm{SHH}$ pathway (Fig. 1B) $(15,45,46)$. Therefore, the binding of N-SHH may present another target in cancer drug studies. For that reason, 5E1 antibody against N-SHH (Fig. 1B) was analyzed in a mouse model of pancreatic cancer, and was found to have a promising effect in the reduction of tumor size and angiogenesis (47). The final interaction between N-SHH ligand and PTCH1 may occur in either an auto- or paracrine way (40), which will be discussed below in the present review.

PTCH1 protein. The PTCH1 receptor, encoded by the PTCH1 gene at 9q22.32, is composed of 1,447 amino acids, arranged in 12 transmembrane helices, two extracellular domains (1 and 2) that can attach extracellular ligand N-SHH and one cytoplasmic carboxyl-terminal domain (48). Mutations in the PTCHI gene lead to an autosomal dominant, multisystem disorder known as Nevoid basal cell carcinoma syndrome, also known as the Gorlin-Goltz syndrome (49). The patched protein family also includes PTCH2 receptor (50). Although both PTCH1 and PTCH2 can bind to Hedgehog ligands with the same affinity, PTCH2 appears to have a lower ability to inhibit the SMO protein $(20,45,51)$. PTCH1 acts as a negative regulator of the SHH pathway by inhibiting SMO protein from translocating to the plasma membrane (Fig. 1A). The mechanism of this inhibition is not yet fully understood; however, recent studies have suggested the involvement of cholesterol or another sterol lipid in this regulation $(52,53)$. Following $\mathrm{SHH}$ pathway activation, the blockade of PTCH1 is abolished and the receptor undergoes internalization, while SMO protein is exposed on the cell surface in the primary cilium (54). PTCH1 subsequently undergoes endocytosis, followed by ubiquitination and lysosomal degradation through E3 ubiquitin ligase SMAD specific E3 ubiquitin protein ligase 1/2 (Smurf1-2; Fig. 1B).

Smoothened protein. Smoothened protein belongs to the F-class of the G-protein-coupled receptor superfamily and is a key intracellular positive $\mathrm{SHH}$ pathway regulator $(55,56)$. Research on SHH signaling in D. melanogaster has indicated that 

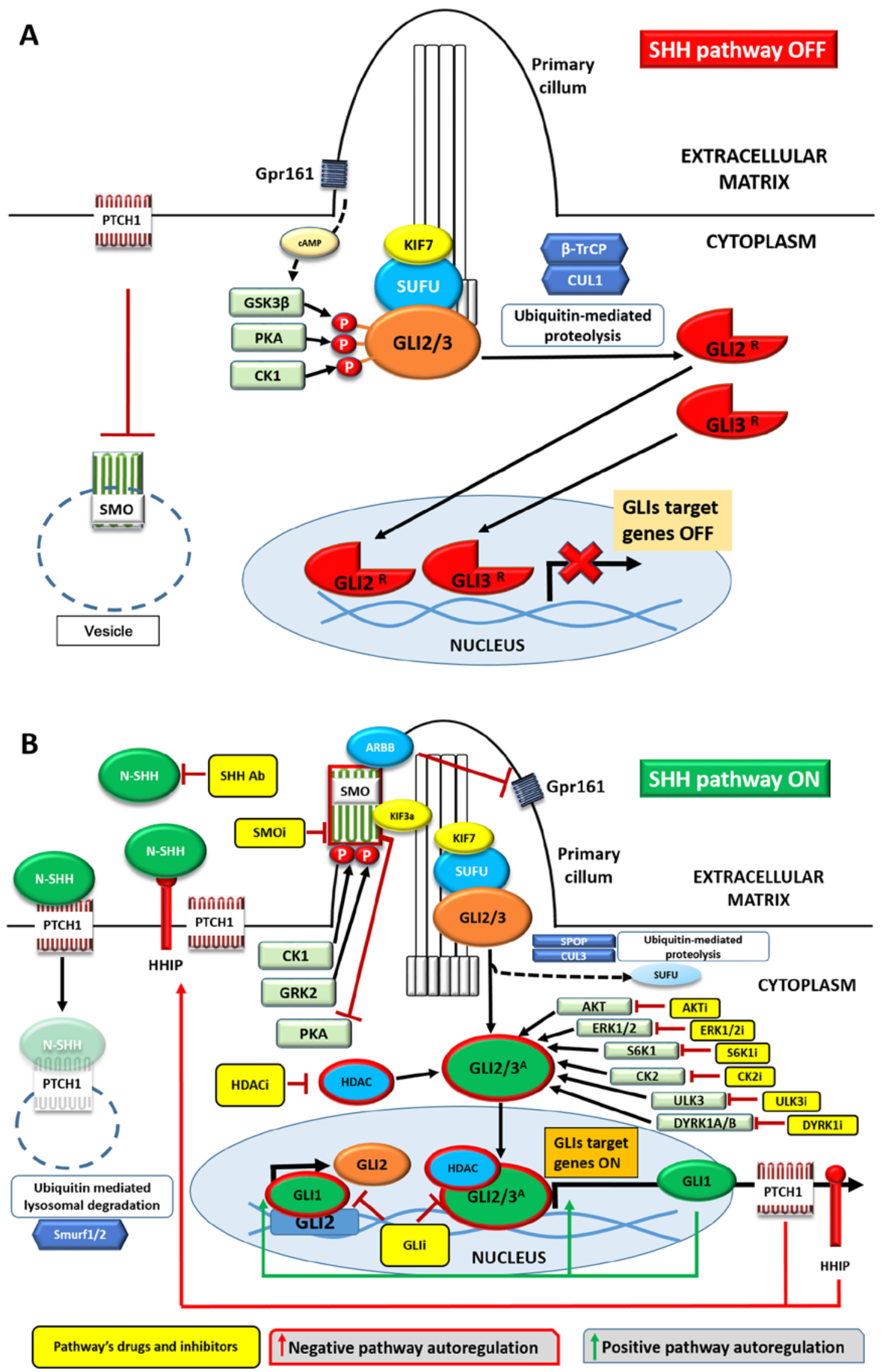

Figure 1. Overview of the SHH pathway in the (A) absence or (B) presence of the SHH ligand. Negative signaling regulators are presented in red and positive regulators in green. Transmembrane proteins are shown as rods or trails, SHH pathway elements and proteins forming complexes with them as ovals, kinases as rectangles and proteolytic proteins as hexagons. Yellow rectangles represent drugs inhibiting/blocking the specific cellular components. Activated proteins are surrounded by red borders. See main text for details. Ab, antibody; i, inhibitor; SHH, Sonic Hedgehog; PITCH1, pitched 1; SMO, smoothened, frizzled

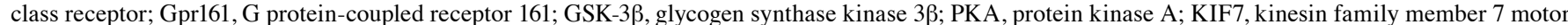
protein; CUL1, $\beta$-TrCP, $\beta$ transducin repeat-containing protein; cullin 1; GRK2, G protein-coupled receptor kinase 2; HDAC, histone deacetylase. 
Table I. Main components of the Sonic Hedgehog pathway in mammals.

\begin{tabular}{|c|c|c|c|}
\hline $\begin{array}{l}\text { Mammalian } \\
\text { gene }\end{array}$ & $\begin{array}{c}\text { Protein, } \\
\text { full name (aliases) }\end{array}$ & $\begin{array}{c}\text { Post-translational } \\
\text { protein modifications (Refs.) }\end{array}$ & Protein function (Refs.) \\
\hline $\mathrm{SHH}$ & $\begin{array}{l}\text { SHH, Sonic Hedgehog } \\
\text { signaling molecule }\end{array}$ & $\begin{array}{l}\text { Autocatalytic cleavage into C-SHH and } \\
\text { N-SHH } \\
\text { Addition of cholesterol and palmitic acid } \\
\text { moiety to N-SHH (39-42) }\end{array}$ & $\begin{array}{l}\text { Upstream, positive regulator of } \\
\text { SHH signaling; ligand for PTCH1 } \\
\text { receptor }(16,20,46)\end{array}$ \\
\hline PTCH1 & $\begin{array}{l}\text { PTCH, patched } 1 \\
\text { (PTC, BCNS, PTC1) }\end{array}$ & $\begin{array}{l}\text { Conformational changes of protein to } \\
\text { enable binding of N-palmitoyled residue } \\
\text { of SHH ligand ( } 48 \text { ) }\end{array}$ & $\begin{array}{l}\text { Receptor for SHH protein; negative } \\
\text { SHH signaling regulator; suppress the } \\
\text { activity of SMO protein }(20,45)\end{array}$ \\
\hline$S M O$ & $\begin{array}{l}\text { SMO, smoothened, } \\
\text { frizzled class receptor } \\
(\mathrm{Gx}, \mathrm{CRJS}, \mathrm{SMOH})\end{array}$ & $\begin{array}{l}\text { Phosphorylation by PKA, GSK } 3 \beta \text { and CK1 } \\
\text { Translocation into primary cilia with } \\
\text { ARBB }(18,59)\end{array}$ & $\begin{array}{l}\text { Atypical G-coupled receptor; positive, } \\
\text { SHH pathway signal carrier }(17,55)\end{array}$ \\
\hline GLII & $\begin{array}{l}\text { GLI1, GLI family zinc } \\
\text { finger } 1 \text { (GLI, PPD1) }\end{array}$ & $\begin{array}{l}\text { Translocation into primary cilia (21) } \\
\text { Dissociation from SUFU (21) } \\
\text { GLI2 and GLI3 proteolytic truncation }\end{array}$ & $\begin{array}{l}\text { Downstream effector of SHH } \\
\text { signaling; zinc-finger transcriptional } \\
\text { activator }(20,21,70)\end{array}$ \\
\hline GLI2 & $\begin{array}{l}\text { GLI2, GLI family zinc } \\
\text { finger } 2 \text { (CJS; HPE9) }\end{array}$ & $\begin{array}{l}\text { suppression (70) } \\
\text { Phosphorylation, ubiquitination, } \\
\text { sumoylation, acetylation, deacetylation (70) }\end{array}$ & $\begin{array}{l}\text { Downstream effector of SHH } \\
\text { signaling; zinc-finger transcriptional } \\
\text { activator/repressor }(20,21,70)\end{array}$ \\
\hline GLI3 & $\begin{array}{l}\text { GLI3, GLI family zinc } \\
\text { finger } 3\end{array}$ & & $\begin{array}{l}\text { Downstream effector of } \mathrm{SHH} \\
\text { signaling; zinc-finger transcriptional } \\
\text { activator/repressor }(20,21,70)\end{array}$ \\
\hline
\end{tabular}

biochemical processes, such as phosphorylation or sumoylation, are required to obtain full SMO activity (57). In mammalian cells, ciliary localization of this molecule appears to be crucial for SMO activation, as well as post-translational SMO modifications, which are analogous to those in Drosophila cells (58). The ciliary translocation of SMO occurs following phosphorylation by a $\beta$-adrenergic-receptor kinase ( $\mathrm{G}$ protein-coupled receptor kinase 2) and is followed by an interaction between cytosolic $\beta$-arrestin (ARBB) and clathrins (59). Following ciliary translocation, SMO is further phosphorylated by casein kinase $1 \alpha$, and then SMO- $\beta$-arrestin complex recruits motor protein kinesin family member $3 \mathrm{~A}$ (Kif3A), which consequently interacts with the kinesin family member 7 motor protein (KIF7)-SUFU-GLI2/3 ciliary located complex (Fig. 1B) (60). The SMO protein is the main anticancer treatment target among all SHH pathway proteins (61). Several SMO inhibitors are in clinical trials, and three of them (vismodegib, sonidegib and, in November 2018, glasdegib) have been approved for selected cancer treatment by the US Food and Drug Administration (FDA) $(61,62)$. However, this molecular treatment has certain limitations, including the development of drug resistance due to frequent SMO mutations, as well as the presence of alternative SMO-independent mechanisms of GLI transcription factor activation $(63,64)$, which are discussed in the following paragraphs.

GLI proteins. Cubitus interruptus has been identified as a transcription factor of the Hedgehog pathway in D. melanogaster $(41,65)$. In mammals, this protein has three analogs (the GLI1, GLI2 and GLI3 molecules), which belong to the Kruppel zinc-finger transcription factor family (66). The lack of a repressor domain in GLI1 protein structure suggests that this molecule may act only as a transcription activator, while GLI2 and GLI3 possess both repressive (GLI2/3 ${ }^{\mathrm{R}}$; Fig. 1A) and activating (GLI2/3 ${ }^{\mathrm{A}}$; Fig. 1B) properties (20). Furthermore, several isoforms of GLI1 and GLI2 (called GLI $\triangle \mathrm{N}$ or tGLI), which are the products of alternative splicing, have been identified in human tissues (65). tGLI1 has been detected only in cancer samples and been associated with aggressive behavior of the disease (67-69). In the absence of SHH, GLI2/3 are attached to the SUFU molecule in the ciliary location by KIF7 (Fig. 1A). GLI2/3 underwent phosphorylation by glycogen synthase kinase (GSK)-3 $\beta$, protein kinase A (PKA) and CK1, which is triggered by cyclic AMP produced by $\mathrm{G}$ protein-coupled receptor 161 (Gpr161). Such action causes proteolytic cleavage of GLIs' $\mathrm{C}$ terminus by cullin 1 (CUL1) and $\beta$ transducin repeat-containing protein $(\beta-\operatorname{TrCP})$, leading to the removal of their transcriptional activation domain. Cleaved GLI2/3, in the form of GLI2 ${ }^{\mathrm{R}}$ and $\mathrm{GLI} 3^{\mathrm{R}}$, translocates to the nucleus and act as inhibitors/repressors after binding to regulatory regions of SHH target genes $(21,70)$.

Following the activation of the canonical SHH pathway, the SMO- $\beta$-arrestin complex inhibits Gpr161 and cyclic adenosine monophosphate-dependent PKA (Fig. 1B) (71), which blocks the phosphorylation and proteolytic cleavage of GLI2/3. Subsequently, the GLI2/3 KIF7/SUFU/GLI2/3 complex dissociates, and full-length GLIs undergo several posttranslational modifications, including phosphorylation, ubiquitination and sumoylation (70), and may simultaneously undergo proteolysis mediated by CUL3 and speckle-type POZ protein (72). The activity of GLI2 ${ }^{\mathrm{A}}$ and $\mathrm{GLI} 3^{\mathrm{A}}$ transcription factors may then be upregulated by various cytoplasmic factors on their way to the nucleus. There are several protein kinases [casein kinase II (CK2), protein kinase B (AKT), extracellular signal-regulated kinase 1/2 (ERK1/2), ribosomal protein S6 kinase 1 (S6K1), 
dual specificity tyrosine phosphorylation regulated kinase $1 \mathrm{~B}$ (DYRK1B) or unc-51 like kinase 3 (ULK3)] (73), which phosphorylate GLI2/3 ${ }^{\mathrm{A}}$ (Fig. 1B), thus promoting GLI translocation into the nucleus. Acetylation/deacetylation of GLIs is another important factor that regulates their transcriptional activity (70). Acetylation of GLI1/2 by p300/CBP complex prevents GLIs from attaching to DNA and provides nuclear export through exportin 1 and LAP2 proteins $(70,74)$. On the contrary, GLI deacetylation by histone deacetylase HDAC1 enables them to interact with genomic DNA (75). Of note, HDACl is upregulated by GLIs; therefore, the HDAC1-GLIs interaction forms a positive feedback loop with the SHH pathway (70,75). A significant role of primary cilium in the functioning of the GLI proteins has been recently reported. In the absence of the SHH ligand, GLI2/3-SUFU complexes are transported to the tip of the cilium by kinesin through the microtubule cytoskeleton, while GLI2 translocation to the cell nucleus following ligand stimulation occurs through dynein-2 (76). The in vivo studies by Wong et al (77) and Han et al (78) revealed that the removal of the Kif3a allele, which is essential for cilia formation, leads to the inhibition of both BCC and medulloblastoma, respectively. However, this effect was observed only in lesions overexpressing the $S M O$ gene, but not the constitutively active GLI2 gene. Therefore, the primary cilium components could be a molecular target for SMO-dependent neoplasms $(77,78)$.

Due to frequent mutations in the SMO receptor, which lead to cancer resistance to previously mentioned SMO-targeted drugs (64), blocking cytoplasmic/nuclear GLI-activator proteins is one of the recently identified targets $(30,79)$. It has been found that CK2, DYRK1B and S6K1 protein kinases, as well as HDAC1, do not require SMO-dependent activation of the SHH pathway to activate GLIs (64). This observation provides reasoning for examining the activity of several potential drugs, including CIGB-300 and CX-4945 targeting CK2 (80), CCI-779 and RAD001 targeting S6K1 (81), BVD-523 targeting ERK1/2 (82), MK2206 targeting AKT (83), AZ191 inhibiting DYRK1B (84) and SU6668 targeting ULK3 (85). It has also been reported that $\mathrm{HDAC1}$ deacetylation activity is successfully blocked by 4SC-202 (17), with GLI-DNA-interaction inhibitors (glabrescione B and GANT61) as well as GLI2 destabilizers (arsenic trioxide and pirfenidone) (Fig. 1B) (17). It is worth noting that the GLI proteins are also involved in other cancer-related pathways, which are discussed below in the present review.

\section{Role of microRNAs (miRNAs/miRs) in upstream SHH gene regulation}

The $\mathrm{SHH}$ ligand is a major molecule that activates $\mathrm{SHH}$ signaling. It is, therefore, of no surprise, that studies regarding the upstream regulation of the $S H H$ gene have been performed to complete the understanding of the role of the SHH pathway in carcinogenesis. The available data are schematically presented in Fig. 2. Due to the important role of SHH signaling in the CNS formation during fetal life, the majority of studies are based on CNS diseases associated with $\mathrm{SHH}$ pathway alterations. In this regard, Schachter and Krauss (86) observed, in a mouse model of holoprosencephaly, that the activation of the SHH gene was regulated by zinc finger protein 2 (ZIC2). ZIC2 protein belongs to the zinc-finger transcription factor family, and its deficiency results in holoprosencephaly 5 , as observed

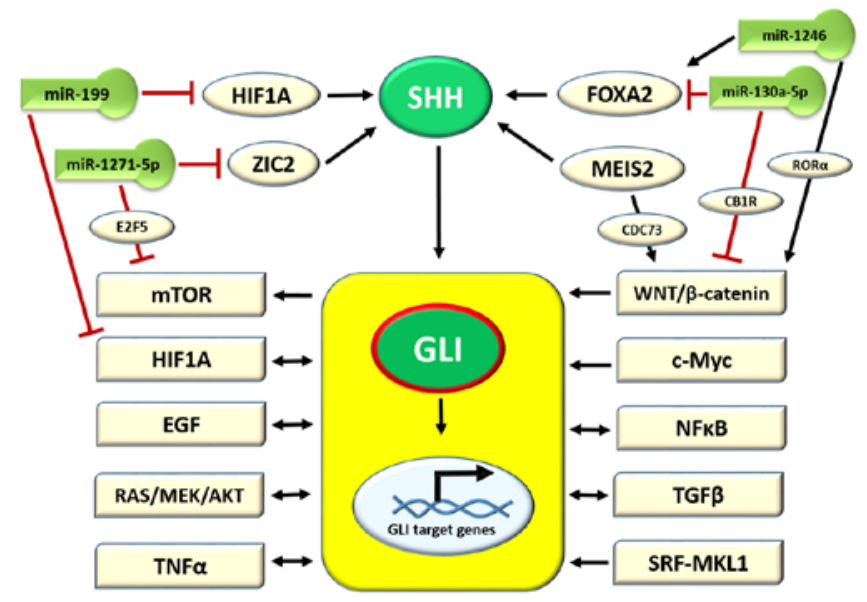

Figure 2. Schematic presentation of upstream regulation of the SHH signaling pathway and its associations with other cancer-related cellular pathways. Proteins are presented by oval shapes, microRNAs by hairpins and pathways by cropped rectangles. SHH, Sonic Hedgehog; mTOR, mammalian target of rapamycin; HIF, hypoxia-inducible factor; EGF, epidermal growth factor; TNF, tumor necrosis factor; $\mathrm{NF}-\kappa \mathrm{B}$, nuclear factor $\kappa \mathrm{B}$; TNF, tumor necrosis factor.

by Barratt and Arkell (87), also in a murine model. In addition, ZIC2 activity is regulated by the miRNA/miR molecule, miR-1271-5p, as reported by Chen et al (88) in an in vitro study on AML. In turn, miR-1271-5p inhibits carcinogenesis in ovarian cancer (OC) and negatively regulates the mechanistic target of rapamycin kinase (mTOR) pathway through the E2F5 transcription factor protein (89). Another study on $\mathrm{SHH}$ gene activation in a CNS murine model revealed the positive role of forkhead box protein A2 (FOXA2) transcription factor in this process (Fig. 2), while the lack of FOXA2 was found to result in a lethal birth defect known as congenital diaphragmatic hernia ( $\mathrm{CDH})(90)$. The FOXA2/SHH axis is also negatively regulated by the miR-130a-5p molecule, which has been found to be overexpressed in $\mathrm{CDH}$ (90). The progression of gastric cancer is associated with a decreased expression of miR-130a-5p; in turn, this deficiency causes an upregulation of Wnt/ $\beta$-catenin signaling by targeting cannabinoid receptor 1 (Fig. 2) (91). Other studies on melanoma progression and hepatocellular carcinoma demonstrated that FOXA2 was activated by the miR-1246 molecule and, in turn, triggered the Wnt/ $\beta$-catenin pathway by retinoid-related orphan receptor $\alpha$ nuclear receptor (Fig. 2) $(92,93)$. A myeloid ecotropic insertion site 2 (MEIS2) transcription factor is another molecule that activates the expression of the $\mathrm{SHH}$ gene for patterning the mandibular arch during fetal development, as observed by Fabik et al (35) in a mouse model. The upregulation of MEIS2 was observed in castration-resistant prostate cancer (PC) (94) and hepatocellular carcinoma, where its isoform MEIS2C activates the $\mathrm{Wnt} / \beta$-catenin pathway by interacting with the CDC73 molecule (95). The hypoxia-inducible factor 1- $\alpha$ (HIF1A) transcription factor is an important molecule triggered by hypoxia in the cells and tissues of fetal and mature organisms. It has been observed that HIF1A activates SHH secretion in the frontonasal ectodermal zone during upper jaw development (96). Furthermore, the upregulation of HIF1A and, indirectly, the HIF1A pathway is halted by the miR-199b molecule (Fig. 2) (96). In conclusion, SHH secretion is regulated by cellular transcription factors, which in turn are mostly 
regulated by miRNA molecules involved in the regulation of various cellular pathways (Fig. 2).

\section{Activation of the target genes of the SHH pathway via GLI factors and crosstalk with other cellular pathways}

Several dozen target genes of GLI1-3 have been identified, which are summarized in Table II. Of note, GLI $2 / 3^{\mathrm{A}}$ stimulates the expression of $G L I 1$, which in turn recognizes the same DNA motive in target genes (5'-GACCACCCA-3') as

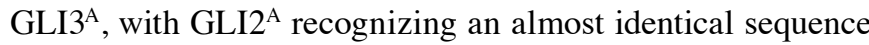
(5'-GAACCACCCA-3') (15). Therefore, the expression of GLII acts as a positive feedback loop for SHH signaling (Fig. 1B) (41). On the contrary, two genes of the SHH pathway negative loop are simultaneously activated by GLIs: PTCHI (97) and hedgehog interacting protein (HHIP); once their protein products reach the plasma membrane, $\mathrm{PTCH}$ and HHIP may decrease the rate of SHH signaling, due to their binding to the extracellular N-SHH ligand (41) (Fig. 1B). Other genes activated by GLI1-3 encode proteins that are involved in the processes of cell proliferation (MYCN proto-oncogene, bHLH transcription factor), cell cycle regulation (CCNDI), angiogenesis (VEGF) and cell survival (BCL2) (37,98). They are also responsible for the stimulation of mechanisms strongly associated with tumorigenesis, such as activating invasion and metastasis [genes encoding matrix metallopeptidases and transforming growth factor (TGF)- $\beta$ ], cell immortality maintenance (gene encoding telomerase reverse transcriptase) or avoiding immune destruction [genes encoding interleukin (IL)-4 and suppressor of cytokine signaling 1]. Therefore, since the SHH pathway interacts with the molecular events important for cancer development and progression, it may be a promising target for anti-tumor therapy (37).

GLI-activated genes (Table II) are associated with various pathways in the cell, which determine the cell's fate and play an important role in tumorigenesis. As previously mentioned, certain cellular pathways are regulated by miRNA molecules, which indirectly act on the SHH pathway through the regulation of the $\mathrm{SHH}$ gene expression. Furthermore, GLIs activate the expression of genes involved in cellular signaling. However, it has also been observed that different pathways may upregulate components of the SHH pathway, and these interactions are schematically presented in Fig. 2. The hypoxia-induced HIF1A pathway triggers $S H H, S M O$ and GLI expression, thus influencing cell stemness and epithelial-to-mesenchymal transition (EMT) in cholangiocarcinoma (99). On the contrary, GLI1 is necessary for hypoxia-modulated EMT and invasiveness of MDA-MB-231 breast cancer cells (100). It was observed in a previous study that the KRAS proto-oncogene of the MAPK/ERK pathway increases GLI1 transcriptional activity and the expression of SHH pathway target genes in gastric cancer (101). The epidermal growth factor (EGF) pathway is associated with $\mathrm{SHH}$ in a complex way: The simultaneous activation of the SHH/GLI and EGF pathway synergistically induced oncogenic transformation of human keratinocytes, an effect that was dependent on the activation of MAPK/ERK signaling (21). The influence of AKT protein on PI3K/AKT/mTOR signaling leads to nuclear translocation, and elevated activity and stability of GLI1 (Fig. 1B) in melanoma (102) and OC cells (103). Moreover, certain studies have revealed that the main tumor suppressor protein, $\mathrm{p} 53$, plays a role in the inhibition of transcriptional activity, nuclear translocation, protein stability and the disruption of the DNA binding ability of GLI1 (63).

The induction of the expression of SNAIL, proto-oncogene Int- 1 homolog and secreted frizzled-related protein 1 by GLIs indicates the impact of SHH on the Wnt/ $\beta$-catenin pathway (104). Different analyses of hair follicle morphogenesis and development have revealed a key regulation of the $\mathrm{NF}-\kappa \mathrm{B}$ pathway upon Wnt and SHH signaling (105). Research on gastrointestinal stromal tumors has indicated an association between $\mathrm{SHH}$ and $\mathrm{PI} 3 \mathrm{~K}$ and mitogen-activated protein kinase pathways (106). The activation of the c-MYC pathway induces the upregulation of GLII, while both 10058-F4 and GANT61, c-MYC and GLI1 inhibitors respectively, have been found to increase apoptosis and reduce the viability of the Burkitt lymphoma cells (107). Research on drug-resistant BCC cells has revealed a novel activation of GLII expression triggered by transcription factor serum response factor together with its co-activator, megakaryoblastic leukemia 1 (108).

The differential activation of the SHH pathway has been observed in systemic sclerosis. The enzyme HHAT, which catalyzes the attachment of palmitate onto the SHH molecule, is regulated in a TGF- $\beta$-dependent manner and, in turn, stimulates TGF- $\beta$-induced long-range hedgehog signaling to promote fibroblast activation and tissue fibrosis (109). Last but not least, research on PC3 and DU145 PC cell lines has demonstrated that the tumor necrosis factor $\alpha$-triggered mammalian target of rapamycin (TNF $\alpha / \mathrm{mTOR}$ ) pathway is connected with GLI activation by S6K1 (Fig. 1B) (110). The list of the complex associations between $\mathrm{SHH}$ and other pathways involved in tumorigenesis is still growing, suggesting the pivotal role of GLI modulation in cancer development (21).

\section{Non-canonical, GLI-independent activation of SHH signaling}

Previous studies have revealed that the SHH canonical SHH/PTCH1/SMO/GLI pathway may trigger different cellular mechanisms without activating GLI transcription factors $(20,111)$. This activity was divided into two modules: Module 1 included those not demanding SMO protein, and module 2 those activated by SMO but not requiring GLIs $(20,111)$. However, it should be noted that other studies merged 'non-canonical SHH activation' with 'GLI activation' via other (not SHH/PTCH1/SMO) cellular pathways (63), interactions that were discussed in the previous section. Both modules are presented in Fig. 3. According to module 1, in the absence of the SHH ligand (Fig. 3A), phosphorylated cyclin $\mathrm{B} 1$ [active mitosis promoting factor (MPF)] is bound to PTCH1 during $\mathrm{G} 2 / \mathrm{M}$ cell cycle transition, thus decreasing the cellular proliferation rate, as observed in 293T cells (112). On the contrary, PTCH1-mutant or SHH-stimulated BCC cells (with wild-type p PTCH1) were characterized by MPF nuclear translocation and an increased proliferation rate (Fig. 3A, right panel) (113). The impact of PTCH1 activation on apoptosis relies on caspase-3 activity (Fig. 3A, left panel). In the absence of $\mathrm{SHH}$, it cleaves C-terminal PTCH1 domain $\left(\mathrm{Asp}^{1392}\right)$, thus releasing caspase recruitment domain family member 8 (CARD8) protein, and the adaptor protein four 
Table II. Sonic Hedgehog signaling target genes and their impact on cells or the SHH pathway.

\begin{tabular}{|c|c|c|c|}
\hline Gene & Protein, full name & Function & (Refs.) \\
\hline$A B C G 2$ & $\begin{array}{l}\text { ABCG2, ATP binding cassette subfamily } \\
\text { G member } 2 \text { (Junior blood group) }\end{array}$ & $\begin{array}{l}\text { ABC transporters, cellular defense mechanism of } \\
\text { xenobiotics removal }\end{array}$ & (197) \\
\hline$A L D H 1 A 1$ & $\begin{array}{l}\text { ALDH1A1, aldehyde dehydrogenase } 1 \\
\text { family member A } 1\end{array}$ & $\begin{array}{l}\text { Metabolism of alcohol and retinol, stemness of } \\
\text { cancer cells }\end{array}$ & $(177,198)$ \\
\hline$B C L 2$ & BCL2, BCL2 apoptosis regulator & Inhibition of apoptosis & $(199)$ \\
\hline BIRC5 & $\begin{array}{l}\text { baculoviral IAP repeat containing } 5 \text {, } \\
\text { survivin }\end{array}$ & Inhibition of apoptosis & $(173)$ \\
\hline$B M P 4$ & BMP4, bone morphogenetic protein 4 & $\begin{array}{l}\text { Ligand of the TGF- } \beta \text { superfamily of proteins, regulation } \\
\text { of heart and teeth development and adipogenesis }\end{array}$ & $(200)$ \\
\hline CCND2 & Cyclin D2 & Cell cycle inhibition & $(37)$ \\
\hline$C D 24$ & $\mathrm{CD} 24$ & $\begin{array}{l}\text { Modulation of growth and differentiation of B cells, } \\
\text { neutrophils and neuroblasts; association with stemness } \\
\text { state of cancer stem cells }\end{array}$ & $(201)$ \\
\hline $\mathrm{CDH} 2$ & $\mathrm{CDH} 2, \mathrm{~N}$-cadherin & $\begin{array}{l}\text { Cell adhesion molecule; development of nervous } \\
\text { system and formation of bone and cartilage; EMT in } \\
\text { cancer development }\end{array}$ & $(190)$ \\
\hline$C D K 1$ & CDK1, cyclin-dependent kinase 1 & $\begin{array}{l}\text { Essential kinase for } \mathrm{G} 1 / \mathrm{S} \text { and } \mathrm{G} 2 / \mathrm{M} \text { phase transitions; } \\
\text { cell cycle control }\end{array}$ & $(202)$ \\
\hline$F G F 3 / 4$ & FGF3/4, fibroblast growth factor $3 / 4$ & Mitogenic and cell survival activities & $(200)$ \\
\hline FOXM1 & FOXM1, Forkhead box M1 & Transcription factor; cell proliferation & $(181,203)$ \\
\hline GLII & GLI1, GLI family zinc finger 1 & Positive feedback of SHH signaling & $(28)$ \\
\hline$H D A C 1$ & HDAC1, histone deacetylase 1 & $\begin{array}{l}\text { Key role in regulation of gene expression, modulates } \\
\text { p53, activates GLIs forming positive loop }\end{array}$ & $(75)$ \\
\hline HHIP & HHIP, hedgehog interacting protein & Decoy for N-SHH ligand; negative regulator of $\mathrm{SHH}$ & $(51)$ \\
\hline$J A G 1$ & JAG1, jagged canonical Notch ligand 1 & $\begin{array}{l}\text { Notch ligand and Wnt signaling pathway; } \\
\text { hematopoiesis }\end{array}$ & $(204)$ \\
\hline$M M P 7$ & MMP7, matrix metalloproteinase 7 & $\begin{array}{l}\text { Cancer invasion and angiogenesis by the proteolytic } \\
\text { cleavage of ECM and basement membrane proteins; } \\
\text { activated by GLI } 2\end{array}$ & $(175)$ \\
\hline$M Y C N$ & $\begin{array}{l}\text { MYCN proto-oncogene, bHLH } \\
\text { transcription factor }\end{array}$ & Cell proliferation, neoplastic transformation & $(205)$ \\
\hline$N A N O G$ & NANOG, Nanog homeobox & $\begin{array}{l}\text { Transcription factor involved in embryonic stem } \\
\text { (ES) cell proliferation, renewal, and pluripotency }\end{array}$ & (17) \\
\hline$P A X 6 / 7 / 9$ & PAX6/7/9, paired box $6,7,9$ & $\begin{array}{l}\text { Fetal development of organs: Eye (PAX6), skeletal } \\
\text { muscle (PAX7), tooth (PAX9) }\end{array}$ & $(206,207)$ \\
\hline PTCH1 & PTCH1, patched 1 & Negative regulator of $\mathrm{SHH}$ pathway & $(41,97)$ \\
\hline SNAII & $\begin{array}{l}\text { SNAI1, snail family transcriptional } \\
\text { repressor } 1\end{array}$ & $\begin{array}{l}\text { Transcriptional repressor which downregulates } \\
\text { the expression of ectodermal genes within the } \\
\text { mesoderm; EMT in cancer development }\end{array}$ & $(205)$ \\
\hline$S O X 2$ & SOX2, SRY-box transcription factor 2 & $\begin{array}{l}\text { Transcription factors involved in the regulation of } \\
\text { embryonic development and in the determination } \\
\text { of cell fate }\end{array}$ & $(208)$ \\
\hline$V E G F A$ & $\begin{array}{l}\text { VEGFA, vascular endothelial growth } \\
\text { factor A }\end{array}$ & $\begin{array}{l}\text { Angiogenesis; induction of proliferation and } \\
\text { migration of vascular endothelial cells }\end{array}$ & $(209)$ \\
\hline
\end{tabular}

EMT, epithelial-to-mesenchymal transition.

and a half LIM domains 2/DRAL (111). This action activates caspase-9, which in turn speeds up the formation of this complex by promoting the activation of caspase-3, leading to caspase-9-dependent apoptosis $(114,115)$. When PTCH1 is inactivated by SHH-binding, CARD dissociates to protein components without caspase-9 activation. This leads to a decreased apoptotic ratio (Fig. 3A, right panel), as observed in $293 \mathrm{~T}$ cells and in a chicken embryo model (115). 
A

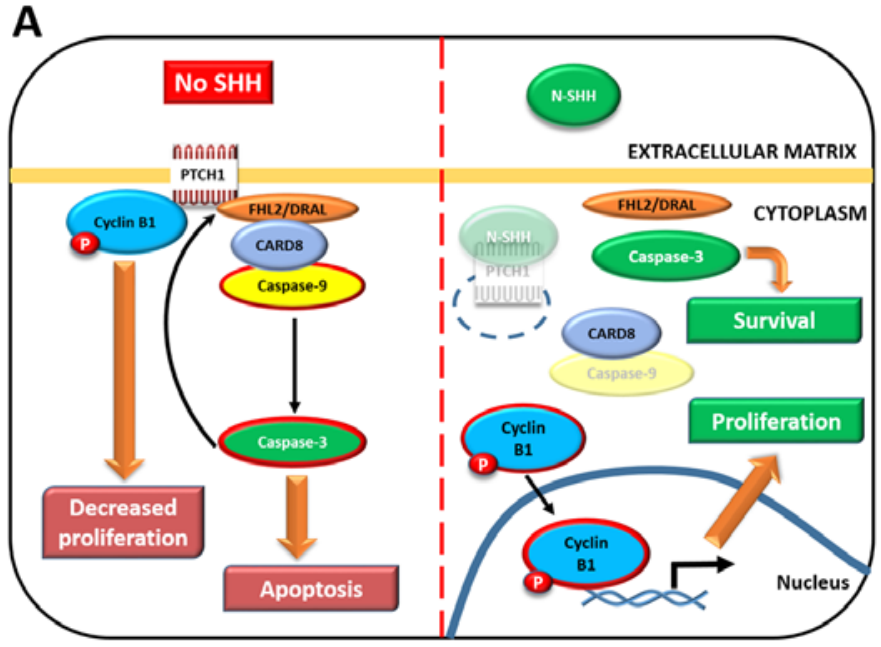

B

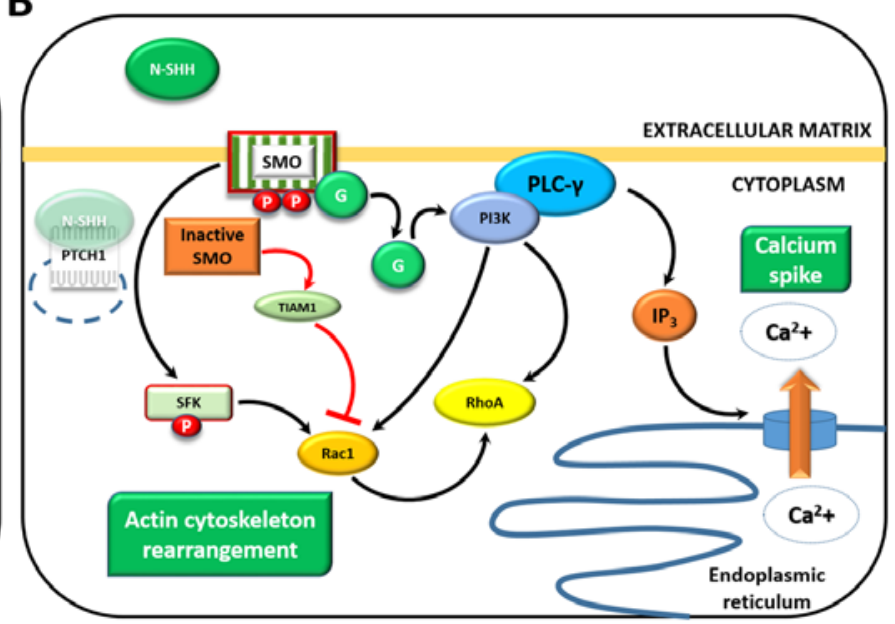

Figure 3. GLI-independent, non-canonical activation of the SHH pathway. (A) Type 1: SMO-independent mechanism (left panel, in the absence of the SHH ligand; right panel, SHH is bound to PTCH1). (B) Type 2: SMO downstream effectors that do not require GLIs; in the presence of SHH only (with the exception of SMO-TIAM1 activity, red arrows). Activated proteins are surrounded by red borders, degraded proteins are partially transparent and thick brown arrows point at activated mechanisms (in cropped rectangles). See main text for details. Adapted from a previous study (112). SHH, Sonic Hedgehog; GLI, GLI family zinc finger; SMO, smoothened, frizzled class receptor; PTCH1, patched 1; TIAM1, TIAM Rac1 associated GEF 1.

Another model of non-canonical SHH activation involves the SMO protein and its downstream effectors, except GLIs (Fig. 3B). Phosphorylated SMO (please see Fig. 1B) uses $\mathrm{G}_{i}$ proteins to activate PI3K kinase, followed by Ras-related C3 botulinum toxin substrate 1 (Rac1) and Ras homologous (Rho) protein activation. Furthermore, Rac1 may be triggered by SMO by phosphorylated SFK kinase. As part of the feedback SMO-Rho pathway, inactive, dephosphorylated SMO inhibits Racl through the TIAM Racl associated GEF 1 protein (Fig. 3B, red arrows) $(111,116)$. Such pathways give a considerably faster cellular response than GLI activation, and result in the rebuilding of the Rho-dependent actin cytoskeleton; stress fiber formation and tubulogenesis, as observed in endotheliocytes, result in tumor-dependent angiogenesis (117). SHH-SMO-regulated Rho-dependent actin cytoskeleton rearrangement resulting in fibroblast migration (118) has been found to be critical to dendrite spine formation in hippocampal and cerebellar neurons (116). The regulation of calcium ions significantly affects the proliferation, differentiation, apoptosis and migration of neuronal and neuronal precursor cells (111). SHH-SMO-G protein activation of phospholipase C- $\gamma$ has been shown to result in the production of PI3K secondary messenger in Rohon-Beard embryonic neurons, which opened calcium channels in SER membrane, thus leading to concentration-dependent $\mathrm{Ca}^{2+}$ transport from SER to cytosol ('calcium spike'; Fig. 3B) (119). Of note, the latter actions of the SHH-SMO non-canonical pathway on nervous tissue play a similarly important role to that of GLI canonical activation during CNS formation $(20,111,116,119)$.

\section{SHH signaling in cancer cells and its implications for the tumor microenvironment}

The different modes of SHH pathway activity in various neoplasms can be divided into three types, which are shown in Fig. 4. Type I (Fig. 4A) is caused by activating mutations in the $S M O$ gene and inactivating mutations in the $P T C H I$ or $S U F U$ genes in tumor cells. This leads to the uncontrolled stimulation of GLI transcription factors and, ultimately, SHH pathway target genes. Consequently, the cells acquire the ability to increase the rate of proliferation, intensify angiogenesis and suppress apoptosis (120). Type I SHH signaling activation has mainly been observed in BCCs, either in sporadic cases or hereditary disorders, such as Gorlin-Goltz syndrome (15). A study that included $42 \mathrm{BCC}$ tumor samples, revealed PTCHI gene inactivation in $67 \%$ cases, increased $S M O$ gene expression in $10 \%$ cases and a $S U F U$ gene mutation in 5\% cases (121). Furthermore, non-epithelial tumors, such as medulloblastoma and rhabdomyosarcoma, are another type of neoplasm that may be associated with type I SHH pathway dysregulation (15). Since this type of regulation is ligand-independent, targeted SHH therapy should affect downstream pathway effectors such as GLI transcription factors (120).

In type II SHH signaling activation (Fig. 4B), the SHH (or IHH) ligand is exposed on the cancer cell surface and may act on the adjacent cancer cells in either an autocrine or juxtacrine manner. Consequently, the SHH pathway becomes reactivated in target tumor cells, and the final effects are the same as those in type I, since they result in cancer development and progression (120). Type II SHH signaling activation in cancer is characterized by the overexpression of SHH components at the mRNA level in cancer cells (but not in stromal cells), as found in four hepatoma cell lines, using the reverse transcription PCR method. Moreover, the immunoreactivity of SHH, PTCH1 and GLI2 proteins was significantly elevated in human hepatocellular carcinoma samples derived from 57 patients, compared to non-cancerous liver tissues (122).

Paracrine, ligand-dependent signaling between tumor and surrounding stromal cells is involved in type III cancer-related SHH alterations (Fig. 4C). The SHH protein can be secreted in excess by cancer cells into the tumor stroma, which leads to the activation of SHH signaling in stromal cells. In response, stromal cells release various SHH signaling target proteins to their microenvironment, which stimulate tumor growth and 
A

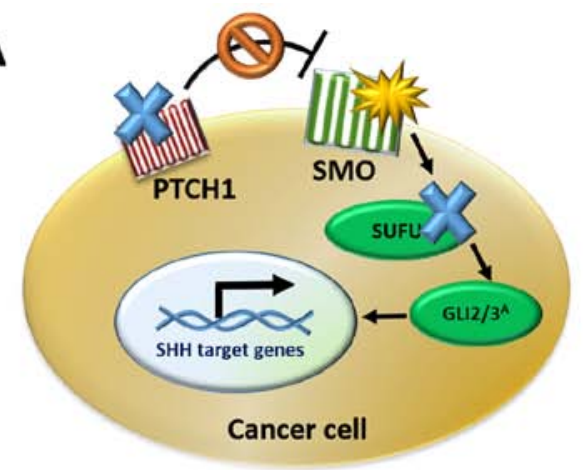

B

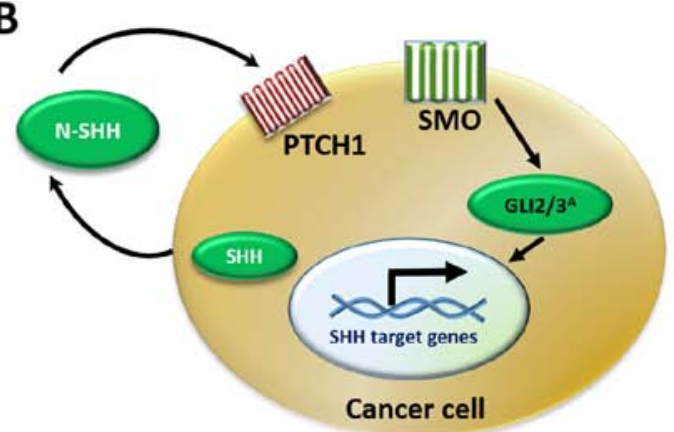

\section{C}
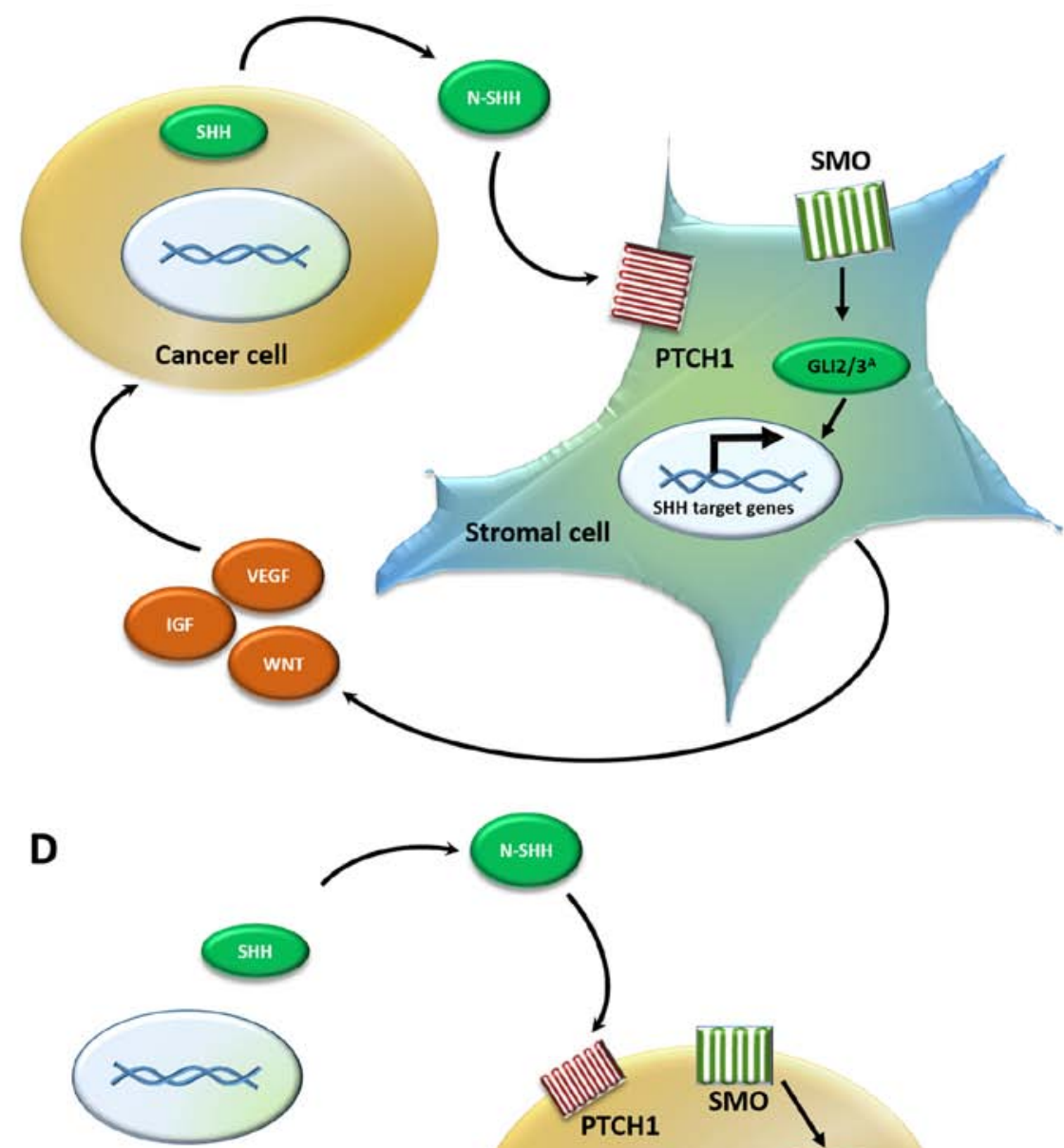

Stromal cell

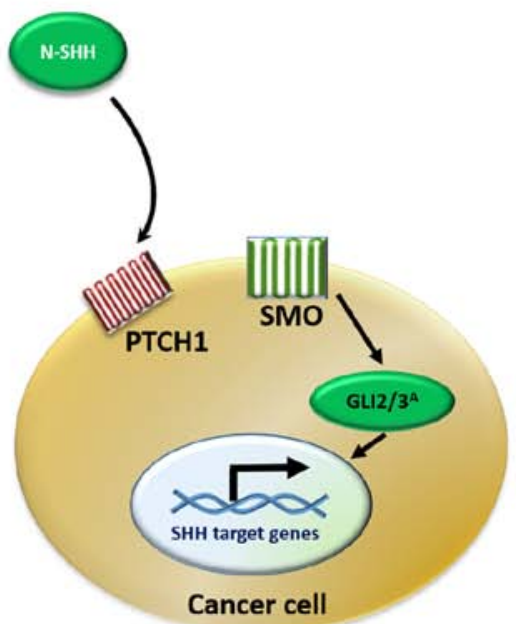

Figure 4. Models of the SHH signaling pathway in cancer. (A) Type I: Ligand-independent activation occurs due to either PTCH1 or SUFU inactivating mutations (blue X) or SMO activating mutations (yellow star), which lead to the constitutive activation of GLI effectors, even in the absence of the N-SHH ligand. (B) Type II: Ligand-dependent autocrine activation. Cancer cells both synthesize and bind to the SHH ligand, resulting in a positive auto-loop activation of the SHH pathway. (C) Type III: Ligand-dependent paracrine activation. Cancer cells secrete the SHH ligand, which is bound by the stromal cells leading to SHH pathway activation in the stroma. The stroma reacts by secreting back various cancer-stimulating signals, such as growth factors to the tumor tissue. (D) Type IIIb: Reverse paracrine activation. Cancer cells receive SHH ligand secreted from the stroma, leading to SHH signaling activation in the tumor cells and upregulation of survival signals. SHH, Sonic hedgehog; PTCH1, patched 1; SUFU, SUFU negative regulator of hedgehog signaling; SMO, smoothened, frizzled class receptor; GLI, GLI family zinc finger.

progression. Furthermore, a reverse paracrine type III mechanism has been observed, in which the PTCH1 receptor on cancer cells binds to the SHH ligand, that is synthesized by stromal cells, which also increases cancer cell viability $(15,120)$. This type of regulation (Fig. 4D) was observed in a pancreatic ductal adenocarcinoma mouse model (123) and human pancreatic 
and metastatic cancer specimens (123). The expression of $\mathrm{SHH}$ and $I H H$ was elevated in tumor cells; however, stromal GLII mRNA levels were found to be 13-150-fold higher than those in cancer cells, suggesting a paracrine SHH signaling activation in stromal cells (123). In addition, the association between SHH and GLII mRNA levels has been found in stromal cells, but not in tumor cells derived from 22 samples of primary human tumor colorectal adenocarcinoma xenografts (124).

With regards to types II and III SHH pathway activity in tumor tissues, therapy including both anti-SHH ligand molecules, such as an anti-SHH antibody, and SMO and GLI protein inhibitors, may be effective (120). As described above with regards to the activation of GLIs, the existence of both canonical and non-canonical SHH pathways should always be considered in studies on potential SHH pathway-targeted treatments. For certain types of neoplasms, combination therapy, such as treatment with an SHH signaling inhibitor and an inhibitor of another signaling pathway, may be effective. For example, an ongoing clinical phase II trial is evaluating the combination of sonidegib (SMO inhibitor) with buparlisib (PI3K inhibitor) in patients with locally advanced or metastatic BCC (18).

Among the stromal cells of the tumor microenvironment involved in the type III mechanism of SHH signaling in cancer tissue, cancer-associated fibroblasts (CAFs) appear to play an important role (125). CAFs resemble myofibroblasts in terms of morphology and molecular features. They can originate from different cell types, such as resident fibroblasts, mesenchymal stem cells or epithelial cells, resulting in a significant CAF heterogeneity. The signals for CAFs activation may be derived both from factors secreted by cancer cells, such as TGF- $\beta 1$ and IL-6, as well as physical properties of the tumor microenvironment, including hypoxia and ECM stiffness (126). There have been reports on SHH pathway paracrine stimulation in CAFs, either by tumor cells (17) or cancer stem cells (CSCs) (127). Subsequently, CAFs are stimulated to secrete molecules that promote VEGF-dependent tumor angiogenesis and self-renewal in CSCs $(17,127)$. The association between SHH signaling and CAFs was observed in pancreatic ductal adenocarcinoma (128) and mammary gland tumors (127).

Other cells of the tumor microenvironment that can be indirectly affected by the SHH pathway are tumor-associated macrophages (TAMs) (125). Although the role of TAMs in tumor development is still not well-described, certain studies have suggested that the cellular PTCH1/SMO/SUFU/GLI1-3 cascade not only elevates TAM infiltration within the tumor stroma, but also promotes the acquisition of the anti-inflammatory M2 phenotype responsible for tumor tissue avoidance of immune destruction (129). The proposed mechanism responsible for recruiting TAMs to the neoplastic niche includes SHH-ligand-driven CAFs, which secrete molecules, such as granulocyte-macrophage colony-stimulating factor, $\mathrm{C}-\mathrm{C}$ motif chemokine ligand (CCL)2, CCL5 and C-X-C motif chemokine ligand 12. Consequently, the number of cells with immunosuppressive properties, including M2 phenotype-TAMs, myeloid-derived suppressor cells and regulatory $\mathrm{T}$ cells, increase, which leads to a reduction in immune effector cell infiltration (17). The significant role of TAMs in the tumorigenesis of BCC (130) and the subgroup of medulloblastomas with upregulated SHH signaling has been reported (131). The association between TAMs and SHH pathways, as well as their impact on cancer-related immunosuppression, may lead to the discovery of novel cancer immunotherapeutic strategies (131).

\section{Sonic Hedgehog signaling in cancers of the urinary tract}

Kidney cancer. Kidney cancers, otherwise known as renal cell cancers (RCCs), are a group of histologically different tumors (132), which rank 14th in incidence among other neoplasms worldwide (8). Clear cell RCC (ccRCC) is the most common subtype (6) and is associated with unfavorable outcomes (133). ccRCC development is strongly associated with the inactivation of the von Hippel-Lindau tumor suppressor (VHL) gene, which can be hereditary (VHL syndrome) or occurs spontaneously during life (10,134-136). Other alterations in genes such as PBRM1 or $m$ TOR have been identified; however, no specific prognostic or predictive molecular markers of RCC can be recommended for clinical use $(6,10)$. RCC therapy includes surgical and pharmacological treatment in the advanced stages of the disease, including tyrosine kinase inhibitors (TKIs) with sunitinib, the first such drugs to be introduced, and mTOR kinase inhibitors (everolimus) and several others, introduced into clinical treatment over the past decade $(6,137)$.

The first report regarding the expression of $\mathrm{SHH}$ pathway components in ccRCC was published in 2009 (138). Dormoy et al (138) found that the SHH signaling genes were expressed at the mRNA level in various RCC cell lines, independently of $V H L$ gene status. In that study the overexpression of SMO and GLII mRNAs was also revealed by RT-qPCR in RCC tumor tissues, compared with corresponding normal kidney samples in the group of 8 patients. Furthermore, incubation with cyclopamine (SMO inhibitor) decreased ccRCC cell proliferation and increased apoptosis, as well as induced the regression of ccRCC tumors in nude mice (138).

Further studies conducted on human RCC samples have demonstrated the association between $\mathrm{SHH}$ signaling and cancer progression. A study on 140 ccRCC specimens derived from patients with non-metastatic disease revealed a significantly elevated DHH, SHH, PTCH1 and GLI3 protein immunoreactivity in samples assessed as G3 or G4 in Fuhrman's grading system [grades 3 and 4 in International Society of Urologic Pathologists (ISUP) grading (139)] than in those with grade G1 or G2 (ISUP grades 1 and 2) (140). An elevated immunoreactivity of the GLI2 transcription factor was found to be associated with a poor prognosis in a group of 39 patients with metastatic ccRCC treated with sunitinib (141). In addition, in vitro experiments revealed a decrease in the GLI2 protein level by western blot analysis in ACHN cells treated with sunitinib, but not in sunitinib-resistant ACHN cells. Therefore, these results suggested that GLI2 protein may be involved in the mechanism of drug resistance associated with TKI inhibitors in RCC (141). Behnsawy et al (142) demonstrated an association between the activity of $\mathrm{SHH}$ signaling and EMT, an important step of cancer progression, in $\mathrm{RCC}$ cell lines. The recombinant $\mathrm{SHH}$ ligand (r-SHH) not only significantly increased proliferation in RenCa and ACHN cells, but also reduced the mRNA level of E-cadherin, the epithelial marker of EMT, suggesting a stimulating role of the SHH pathway in EMT (142). 
Since several studies have reported a $S H H$ gene upregulation in RCC $(140,142,143)$, the present review focused on the occurrence of the upstream protein and miRNA regulators of SHH expression in RCC. Shang et al (144) analyzed the mRNA expression rates of the ZIC2 gene in 533 ccRCC and 72 normal kidney samples (TCGA database), and found that the overexpression of ZIC2 mRNA was associated with age, TNM, histological grade and a shorter overall survival; thus, this gene can therefore be used as an independent prognostic factor in ccRCC. Jia et al (145) also analyzed TCGA data from 525 patients with ccRCC focusing on SHH-associated FOX family genes, and it was found that FOXA2 mRNA overexpression was associated with poor outcomes.

As previously mentioned, RCC initiation is strongly associated with the $V H L$ gene status, which is inactivated in a broad range of ccRCC cases. The gene encoding VHL protein, which acts as an E3 ubiquitin ligase, is the enzyme responsible for hypoxia-inducible factor (HIF1 $\alpha$ and HIF2 $\alpha$ ) degradation under normoxic conditions (136). Therefore, Zhou et al (146) investigated the expression of SHH pathway genes in normoxia and hypoxia, as well as the association between the SHH signaling components and HIF $2 \alpha$. The mRNA expression of all SHH signaling genes was significantly elevated in RCC cell lines that were cultured under hypoxia, compared with normoxic control RCC cells. Of note, the re-activation of the SHH pathway under hypoxic conditions was independent of $V H L$ expression, with the dual inhibition of HIF2 $\alpha$ and GLI1 activity. Furthermore, the treatment with sh-HIF2a and GLI1 inhibitor GANT61 significantly sensitized RCC cells to ionic radiation. These results demonstrated that the $\mathrm{SHH}$ pathway together with HIF2 $\alpha$ protein may be involved in the molecular mechanisms of RCC radioresistance. In addition, the SMO inhibitor, cyclopamine, was not found to reduce the observed overexpression of GLII under hypoxic conditions, which suggested that GLII expression in RCC cells does not depend on upstream SHH signaling components, but could be induced by different molecular signaling (non-canonical activation) (146). Further evidence provided by Zhou et al (147) confirmed this conclusion and demonstrated an involvement of the PI3K/AKT cascade on the main effectors of the SHH pathway in RCC cells. PI3K/AKT signaling stimulation or inhibition induced or decreased the expression of GLII and $G L I 2$, respectively. It was also demonstrated in vitro and in vivo that the combination of GANT61 with the AKT specific inhibitor, perifosine, was associated with a significantly enhanced therapeutic potential, compared with that of the use of each substance alone (147).

The efficacy of several other SHH inhibitors on kidney cancer treatment has been under investigation over the past few years. Erismodegib, a SMO antagonist, was previously shown to inhibit the survival of the human 786-O RCC line, either alone or, more effectively, in combination with sunitinib and everolimus (148). This antitumor effect was also observed in sunitinib-resistant RCC cells (786-O SuR cells), revealing a novel research direction for RCC therapy. It was also observed that erismodegib combined with sunitinib or everolimus decreased the tumor volume and increased the survival of nude mice with 786-O SuR cell-derived tumor xenografts, confirming previously described results. However, unlike erismodegib, GANT61 had no inhibitory effect on RCC cells (148), indicating that SMO is a more promising selective RCC therapy target than GLI transcription factors.

In a previous study by the authors (143), the expression of SHH pathway components in 37 ccRCC tissue samples, a significant correlation was identified among the expression of almost all SHH signaling genes at the mRNA level. Although the mRNA level of $S H H, S M O$ and GLII was increased in ccRCC samples, compared to the morphologically unaltered kidney tissues, no association was observed between the expression rates of genes and the pathological features of patients. However, at the protein level, western blot analysis of SHH revealed a significant increase of full-length $\mathrm{SHH}$ and a decrease of the C-SHH domain in ccRCC tissues (143). This novel observation may suggest an involvement of the SHH ligand in ccRCC development, and indicate changes in the post-translational modification of this protein during tumor progression.

Bladder cancer. According to the GLOBOCAN database, there were 549,393 new cases of bladder cancer in 2018, which renders this type of cancer as the 11th most common type of cancer worldwide (149). Approximately $90 \%$ of bladder carcinomas are derived from the transitional epithelium (1). Several studies have proven the significance of nicotine and industrial gases in the pathogenesis of this type of cancer $(150,151)$. The disease risk assessment is performed using clinical patient examination, medical imaging and microscopic examination of the resected tumor tissues. The bladder cancer guidelines recommend the tumor-node-metastasis (TNM) system as an appropriate classification system for tumor staging. The treatment of bladder cancer includes transurethral resection of the bladder tumor for initial bladder neoplasms; however, for more advanced tumors, radical cystectomy with lymphadenectomy and additional radio- or chemotherapy are required (1). Genetic and epigenetic alterations of bladder cancer cells, which may be useful prognostic factors or targets for personalized therapy, are under investigation. The molecular profile of non-muscle invasive bladder cancer (NMIBC) differs significantly from muscle invasive bladder cancer (MIBC). In addition, genetic alterations characteristic of low-grade NMIBC, such as fibroblast growth factor receptor 3 (FGFR3) or $R A S$ mutations, can be distinguished among NMIBCs. FGFRI, FGFR3, $P N E N, C C N D 1$ or MDM2 proto-oncogene genes have been identified as potential therapeutic targets, whereas TSC complex subunit 1 or phosphatidylinositol-4,5-bisphosphate 3-kinase catalytic subunit alpha (PIK3CA) mutations may be predictive targets for mTOR or PIK3CA/mTOR inhibitors, respectively $(1,152)$.

In 2012, He et al (153) performed immunohistochemistry (IHC) on 118 human bladder cancer samples. The expression of proteins encoded by the SHH, PTCHI and GLII genes was significantly elevated in tumor tissues, compared to 30 adjacent normal bladder tissues. The increased immunoreactivity of SHH pathway proteins was observed in samples derived from patients with a high pathological stage, the presence of venous invasion and lymph node metastasis. Patients with a positive SHH, PTCHI and GLII expression also exhibited poorer disease-free survival rates, according to Kaplan-Meier analysis (153). Further studies suggested the prognostic value of the SHH pathway protein level in bladder cancer. Nedjadi et al (154) revealed that a high SHH protein 
immunoreactivity in urothelial bladder cancer tissues was associated with the presence of lymph node metastasis; however, no association was identified between $\mathrm{SHH}$ expression and other clinicopathological parameters or patient survival. $\mathrm{SHH}$ overexpression can be associated with the upregulation of MEIS2 (an upstream SHH gene regulator) in bladder cancer lymph node metastasis, as observed by Xie et al (155) in a clinical study on 104 patients with bladder cancer.

The significant role of SHH pathway proteins was observed in the EMT of bladder cancer cells. An HTB-9 transitional bladder cancer cell line, with acquired mesenchymal features due to TGF $\beta 1$ stimulation (T-HTB-9), exhibited an overexpression of the $S H H$ and GLI2 genes at the mRNA and protein levels. Furthermore, following incubation with cyclopamine, and GDC-0449, SMO and GLI1-3 inhibitors, a decrease in the migration, invasion and clonogenicity of T-HTB-9 cells was observed (156). This evidence suggested that inhibitors of the SHH pathway may effectively decrease bladder cancer invasive potential and may thus prove to be useful to bladder cancer treatment. Islam et al (156) examined 22 specimens derived from human bladder cancer. An elevated immunoreactivity of SHH, GLI2, Ki-67 proliferation marker and N-cadherin (mesenchymal cell marker), and a decrease in E-cadherin (epithelial cell marker), were observed in high-grade tumors compared with low-grade tumors, further confirming the participation of SHH signaling proteins in the EMT of human bladder cancer cells (156). Another analysis concerning the association between EMT and the SHH pathway was performed on muscle-invasive T24 and 5637 bladder cancer and non-muscle-invasive KK47 cell lines. The incubation of the cells with recombinant $\mathrm{SHH}$ protein decreased the expression of E-cadherin and enhanced that of $\mathrm{N}$-cadherin and vimentin in all three cell lines. Cyclopamine was found to inhibit cell proliferation and invasiveness; however, the effect was more pronounced in T24 and 5637 cell lines. In vivo studies on nude mice with induced bladder cancer revealed a significant inhibition of muscle-invasive-derived tumor development, which indicated the potential benefits of using SHH pathway-targeted therapy in advanced stages of bladder cancers (157). Of note, Kim et al (158) found that the CpG hypermethylation-induced decrease in $\mathrm{SHH}$ gene expression in bladder cancer cells led to an increase in tumor invasiveness. The lack of SHH ligand decreased the activity of SHH signaling in stromal cells, inhibiting the expression of bone morphogenetic proteins and ultimately stimulating bladder cancer progression (158). Furthermore, the pharmacological inhibition of DNA methylation inhibited the initiation of invasive urothelial carcinoma at the premalignant stage of progression, through the increase in SHH expression in cancer cells (158). These findings were not consistent with previously presented results; thus, further research on the cell-to-cell interactions between bladder cancer and stromal cells in bladder tumors would improve the understanding of the molecular basis of the role of the $\mathrm{SHH}$ pathway in bladder cancer (158).

\section{SHH pathway in gynecological cancers}

Cancers of the female reproductive tract include OC, CC and fallopian tube, uterine, vaginal and vulvar cancers, as well as gestational trophoblastic neoplasms, according to the AJCC Cancer Staging Manual, 8th Edition (159). The involvement of the SHH pathway in the latter has barely been studied since its discovery (160). Ho et al (160) focused on the expression of Kif7 motor protein and GLI1-3 transcription factors, and reported a strong downregulation of the GLII-3 genes at the mRNA level in 4 choriocarcinomas, as well as 50 hydatidiform moles, compared with 19 normal placentas. Although it was proven in that study that the overexpression of Kif7 in the choriocarcinoma cell lines, JAR and JEG-3, suppressed cell migration, the role of $\mathrm{SHH}$ in the development of gestational trophoblastic neoplasms remains unclear (160). Furthermore, only one study focused on SHH expression in vulvar squamous cell carcinoma (VSCC); Yap et al (161) performed semi-quantitative IHC of tissue specimens from 91 VSCC cases for SHH, PTCH1 and GLI1 proteins. Although an increased immunoreactivity of one or more of the assessed proteins was reported, only the decreased expression of PTCHI was associated with an increased risk of developing a local disease recurrence (161).

$O C$. OC ranks 8th in incidence and mortality among cancers affecting women (18th and 14th in both sexes, respectively) worldwide, with almost 300,000 cases and 185,000 deaths in 2018, according to the GLOBOCAN data (8). Epithelial OC accounts for $>90 \%$ of all ovarian malignancies and is classified into five histological subtypes: Serous, mucinous, endometrioid, undifferentiated and clear cell subtypes (162), while $\mathrm{OC}$ advancement is based on the International Federation of Gynecology and Obstetrics (FIGO) staging. Molecular patterns of SHH upstream regulators in OC have only been analyzed by a few studies.

One of the first studies on SHH pathway components in OC was conducted by Levanat et al in 2004 (163). Although an upregulation of GL1 mRNA expression was not observed in a group of 11 ovarian fibromas and 15 ovarian dermoids, higher mRNA levels of SMO and $S H H$ were observed. A frequent mutation of the $P T C H 1$ gene was also identified in the majority of ovarian fibromas, but it was not found to be associated with the expression level of this gene (163). Marchini et al (164) observed the overexpression of ZIC2 in the malignant form of epithelial OC $(n=193)$, compared to low-malignant potential OCs $(n=39)$. In OC cell lines, ZIC2 overexpression was found to increase the growth rate and foci formation of NIH3T3 cells and stimulate anchorage-independent colony formation (164). The data on FOXA2 expression in OC are inconclusive: Salem et al (165) found that its lower mRNA levels promoted OC tumorigenesis, while Peng et al (166) reported high FOXA2 levels in OCs. Loss of heterozygosity of the PTCH1 gene was a frequent observation in OC $(167,168)$, suggesting that the mechanism of SHH pathway activation in $\mathrm{OC}$ is type I. Moreover, the studies regarding somatic mutations in SHH signaling components counted 14\% frequency in a MyPathway study (169).

Further studies identified the association between $\mathrm{SHH}$ signaling and OC progression; Liao et al (170) observed the overexpression of $\mathrm{SHH}$ and patched proteins (assessed by IHC in 80 patients with OC) and GLII mRNA (quantified by qPCR in 37 OCs) in tumor specimens, whereas no changes were observed in ovarian tissue. In addition, the observed molecular alterations were associated with the poorer outcome 
of OC patients. Liao et al (170) also performed a GLI1 ectopic expression experiment on SKOV3 and OVCAR3 OC cell lines and reported the upregulation of tumorigenesis-related genes (i.e., $B C L 2, V E G F$ and genes encoding vimentin and E-cadherin). The incubation of SKOV3, OVCAR3 and OVCA433 cells with KAAD-cyclopamine, an inhibitor of SMO protein, suppressed cancer cell viability, induced apoptosis, and decreased the expression of the aforementioned cancer-related genes (170). However, contrasting results were obtained by Yang et al (171), who did not report higher levels of SHH pathway components nor the target genes in $34 \mathrm{OC}$ tumor samples. Based on the SHH, PTCHI, GLII, HHIP, $S M O$ and $S U F U$ mRNA semi-quantification results (assessed by PCR and qPCR for GLII), as well as patched 1, GLI1 and HHIP proteins (assessed by IHC), the results of that study suggested infrequent involvement of the SHH pathway in OC development (171). In a study by Schmid et al (172), inconclusive results of the expression of SHH signaling and target genes in OC were obtained. In a group of 16 FIGO stage III serous tumors, various expression levels of SHH genes (GLII/2, PTCHI, SHH and SMO; assessed by qPCR) were observed, while $I H H$ and $P T C H 2$ genes were upregulated in the majority of cases (172).

More recent data have confirmed, however, the impact of the SHH pathway in the progression of OC; Ozretić et al (97) analyzed SHH pathway genes in $23 \mathrm{OCs}$, including 16 carcinomas (CA) and 7 atypical proliferative (borderline) tumors. However, higher mRNA levels of GLII and SUFU were observed in OCs, and SUFU levels were found to decrease with increasing FIGO stages. Moreover, a strong positive correlation was observed between the SMO and GLII mRNA levels. In the primary culture of tumor cells obtained from a high-grade ovarian tumor sample (FIGO IIIC), cyclopamine exerted an inhibitory effect on cell proliferation, but only in the first $24 \mathrm{~h}$, whereas GANT61 decreased the proliferation rates of both primary and SKOV-3 cell lines after $72 \mathrm{~h}$ (97). Furthermore, GANT61, unlike cyclopamine, led to the downregulation of GLI2 transcription factor in the cells at the molecular level, rendering it a more effective SHH signaling inhibitor in OC treatment (97).

Recent studies have highlighted the importance of GLI-regulated anti-apoptotic protein survivin (BIRC5) $(97,173,174)$ and matrix metalloproteinase (MMP)-7 (175) as putative markers for OC progression. Zhang et al (175) reported a high immunoreactivity of MMP-7 and GLI2 in tumor tissues from 95 OC patients, and the high expression of MMP-7 protein was found to be associated with poor patient outcomes. The association between the $\mathrm{SHH}$ pathway and MMP-7 expression was proven by demonstrating that ectopic stimulation of SHH in an SK-OV-3 OC cell line increased MMP-7 expression (175).

BIRC5 is an anti-apoptotic protein that acts as a negative regulatory protein that prevents apoptotic cell death; the gene is highly expressed during fetal development and in cancer tissues (176). Trnski et al (173) and Vlčková et al (174) analyzed the association between BIRC5 gene activation and the SHH pathway. The first team worked on A549 and the other experimented on SKOV-3 OC cell lines. Based on BIRC5 promoter inactivation by GANT61 rather than cyclopamine, Vlčková et al (174) proved that BIRC5 was regulated by the GLI2 transcription factor. Trnski et al (173) further revealed, by the addition of the GLI1 activator, that GLI3 was not associated with survivin expression.

Recently, the associations between the SHH pathway and CSC have been studied in high-grade serous OC (HGSOC) (177). Sneha et al (177) analyzed the effects of SHH pathway inhibitors on cell viability and spheroid formation through primary cultures of tumor cells from HGSOC and in nine OC cell lines. The treatment of cells with SHH inhibitors reduced the formation of spheroids with the higher efficacy of GANT61, compared with LDE225 (sonidegib) and salinomycin. In a xenograft model, the formation of tumors with an OVCAR3 origin was inhibited by GANT61 treatment. It was also found that the stemness marker, ALDH1A1, was at least partially dependent on the SHH pathway (177). The association between ALDH1A1 and the SHH pathway through the inhibition of GLIs was also observed in bladder (178) and breast (179) cancer. In conclusion, data have demonstrated that the SHH pathway plays an important role in OC development with GLI1/2 downstream effectors as the key points.

$C C$. The worldwide incidence and mortality numbers of CC in 2018 were approximately 590,000 and 311,000, respectively, with $\mathrm{CC}$ ranking fourth in both categories among other malignancies (8). Although it is known that the pathogenesis and progression of $\mathrm{CC}$ are associated with human papillomavirus (HPV) infection, the involvement of the SHH pathway has also been described. The study by Rojo-León et al focused on the impact of HPV E6/E7 oncogenes on the SHH pathway in transgenic mice that carry eight GLI1-binding sites bound to the firefly luciferase gene (180). An increased GLII expression was observed in the cervix and skin either after exogenous estradiol or E6/E7 oncogene activation (180). Chen et al (181), using a microarray assay, found an increased expression of GLII, SMO, SHH, PTCHI and FOXM1 (GLI target gene) in 70 tumor CCs, compared to 10 normal cervical tissues; the expression patterns of those genes were associated with either the clinical or pathological progression of CC.

The majority of studies describing the role of the $\mathrm{SHH}$ pathway in $\mathrm{CC}$ have been performed using $\mathrm{CC}$ cell lines. Vishnoi et al (182) reported a connection between E6/E7 oncoproteins and SHH activation by analyzing HPV-16 positive SiHa CC cells. In SiHa cells, the SHH components, GLI, $S M O$ and $P T C H 1$, were found to be overexpressed, while their reduced expression was observed following either the addition of cyclopamine or siRNA-mediated E6 gene silencing (182). Wang et al (183) demonstrated that, in a hypoxic environment, the GLII mRNA level in HeLa cells was increased and was accompanied by an enhanced invasion ability, whereas GLII silencing reversed these effects, compromising the invasiveness of HeLa cells. Furthermore, Wang et al (183) observed that the ectopic increase of mir-129-5p resulted in the lower mRNA and protein levels of ZIC2, SHH, GLI1 and GLI2, together with SHH target genes CXCL1, VEGF and ANG2, as well as the inhibition of tumor formation in a mouse xenograft model. These results indicated that mir-129-5p may be a promising target for CC treatment (184). In combination, the available evidence suggested that the SHH pathway is involved in $\mathrm{CC}$ progression. 


\section{SHH pathway in cancers of the male reproductive system}

The testis, penis and prostate may be affected by neoplastic transformation, leading to cancers of the male reproductive system, according to AJCC Cancer Staging Manual, 8th Edition (159). Although DHH is involved in the differentiation of peritubular myoid cells and consequent formation of the testis cord (185), while the SHH is involved in penile development (186), there are no data available on the SHH pathway during testicular or penile tumorigenesis, at least to the best of our knowledge.

$P C$. Prostate gland tumors rank 2 nd in the worldwide cancer incidence among males (4th among all cancers in both sexes) with almost 1.3 million new cases, and 5th in worldwide cancer mortality in males (8th among all cancers in both sexes) with $\sim 359,000$ deaths in 2018 (8). The majority of PCs are associated with defective DNA damage repair molecules, while androgen receptor (AR) signaling also plays an important role in PC pathogenesis, particularly in metastasized cases (187). During fetal life, the AR and SHH pathways play a crucial role in the development of the prostate gland $(188,189)$. Le et al $(188)$ reported that, during prostate development, growth and regeneration, both pathways are indispensable; the $A R$ signaling pathway is superior since, in the murine in vivo model, the expression of AR was essential for urogenital mesenchymal and epithelial cell differentiation, even if the cells overexpressed GLII.

Yamamichi et al (190) reported that in PC epithelial cells (LNCap) and prostate fibroblast cell lines, normal (NPF) and PC-associated (CPF), dihydrotestosterone (DHT) enhanced cell proliferation in all cell types while the inhibition of $\mathrm{SHH}$ signaling by cyclopamine decreased this rate in CPF cells only. The activation of both androgen and SHH signaling enhanced EMT, accelerating PC development, while cyclopamine blocked cancer progression. In addition, DHT (but not SHH) induced the expression of osteonectin, and a high GLII expression and stromal osteonectin expression (as found by IHC) in tumor tissues from 25 patients with PC, were associated with PSA recurrence (190).

A recent study by Zhang et al (191) analyzed the AR and SHH pathways in PC clinical cases. In a large group of 443 patients with primary PC and 96 with benign prostatic hyperplasia, the increased immunoreactivity of $\mathrm{SHH}$ protein was observed in more aggressive tumors (Gleason score of $>7$ ), which was much higher in AR-positive than in AR-negative cancer. Furthermore, SHH was overexpressed in high-grade PC and positively correlated with the expression of both GRP78 (the molecule involved in endoplasmic reticulum stress response) and AR; this suggested that the assessment of SHH protein could be beneficial as a prognostic factor in PC, since SHH overexpression in all patients with $\mathrm{PC}$ with $\mathrm{AR}^{+}$tumors was associated with a shorter disease-specific survival (191). Describing the expression pattern of SHH pathway components in PC, Tzelepi et al (192) analyzed SHH, SMO, PTCH, GLI1, VEGF, CD31 and ki67 protein levels using western blot analysis, IHC and tissue microarrays in large groups consisting of 141 hormone-naive primary PC and
53 castrate-resistant bone marrow metastases, compared to 119 prostate non-neoplastic peripheral zone. First, they observed the crosstalk between prostate cells in healthy tissues; SHH and PTCH1 were primarily expressed in epithelial and stromal cells, respectively, while SMO and GLI1 were expressed in both epithelial and stromal cells. This observation suggested paracrine signaling between epithelial (donor) and stromal (acceptor) cells, followed by SHH pathway activation in all cells (192). The expression pattern was continued in primary PCs with higher SHH and SMO protein levels in PC epithelial cells than those in the non-neoplastic peripheral prostate zone. Of note, in PC metastases, a higher PTCH1 expression was observed in epithelial cells compared with that in stromal cells, while the expression of $S H H$ and GLII did not differ between the two (192). These results suggested an alteration in the mechanisms of SHH signaling in PC and its metastases, as well as its involvement in PC development.

In combination, the available data demonstrate that the SHH pathway plays an important role in PC development, indicating that SHH pathway-targeting drugs should be introduced into PC treatment. Indeed, two phase I and one phase II clinical trials that used LDE225, vismodegib or itraconazole (SMO inhibitors) have been performed (193-195). Although decreased levels of GLI1 were recorded in tumor tissues from patients treated with vismodegib or LDE255, there was no apparent effect on clinical activity. In addition, vismodegib caused side-effects, such as fatigue or nausea, and LDE255 increased the prostate-specific antigen (PSA) serum level $(193,194)$. Treatment with itraconazole, an FDA-approved antifungal drug, demonstrated that a high dose $(600 \mathrm{mg})$ may be beneficial for progress-free survival. However, such a dose has been found to cause hypokalemia $(195,196)$. In summary, drugs targeting the SHH pathway should be further evaluated as an additional modality of PC treatment, given that more studies associated with the interactions between stromal and PC cells in relation to the AR and SHH signaling pathways are being carried out.

\section{Conclusions and future perspectives}

The SHH signaling pathway was identified 40 years ago, and since then, the understanding of the functions of and cellular associations between its components has been considerably increased. Although the SHH-PTCH-SMO-GLI cellular cascade has been widely discussed in several studies, the aim of the present review was to also describe the upstream genetic regulation of the SHH ligand expression. Of note, the activation of SHH biosynthesis relies on proteins with transcription factor properties that are involved in fetal development, tissue renewal and remodeling in the adult body. Indirectly, $\mathrm{SHH}$ is regulated by miRNAs, which also interact with other cellular pathways. GLIs are the main downstream effectors of SHH signaling and their transcriptional activity depends mainly on their release from the SUFU-KIF7 complex triggered by the SMO receptor. Since the upregulation of the SHH pathway, particularly GLIs, is associated with the progression of several types of cancer, specific drugs inhibiting this signaling have been developed. 
Most of them target the SMO receptor; however, due to frequent $S M O / P T C H 1$ mutations that may lead to drug resistance, GLIs can be also activated through other cellular pathways.

In the present review, the focus was placed on analyzing the $\mathrm{SHH}$ pathway components in the kidney, urinary bladder, OC, CC and PC. In all these cancers, including sex hormone-dependent ovarian and prostate tumors, deregulations of SHH pathway components were observed by several authors. Furthermore, the interaction between viral proteins and SHH signaling molecules has been noted in cervical types of cancer, mostly originating from HPV infection. The alterations of the $\mathrm{SHH}$ pathway components in these cancers have often been found to be associated with either the clinical or pathological status of patients. Despite these findings, the $\mathrm{SHH}$ components have not yet been considered as prognostic or therapeutic molecular parameters in gynecological and urogenital cancers. This may have been caused by the unsatisfactory results of older clinical trials with SMO or GLI inhibitors. However, since the knowledge of SHH pathway interactions with other cellular signaling pathways in these malignancies is accumulating and new molecules targeting the $\mathrm{SHH}$ pathway are being developed, it can be expected that new clinical trials will soon be performed. It is also worth noting that limited data are available on the involvement of the SHH pathway in the pathogenesis of penile, fallopian tube, vaginal and vulvar cancer.

\section{Acknowledgements}

Not applicable.

\section{Funding}

The present study was funded by the ST-12 internal funds of the Medical University of Gdańsk, Poland.

\section{Availability of data and materials}

Not applicable.

\section{Authors' contributions}

$\mathrm{AKC}, \mathrm{ZK}$ and PMW performed the literature search, wrote the manuscript and prepared the figures. All the authors confirm the authenticity of all the raw data. All the authors have read and approved the final version of this manuscript.

\section{Ethics approval and consent to participate}

Not applicable.

\section{Patient consent for publication}

Not applicable.

\section{Competing interests}

The authors declare that they have no competing interests.

\section{Authors' information}

The ORCID numbers of the authors of the present study are as follows: AKC, 0000-0002-2942-6270; ZK, 0000-0002-9801-8166; and PMW, 0000-0002-4310-1616.

\section{References}

1. Bellmunt J, Orsola A, Leow JJ, Wiegel T, De Santis M, Horwich A and on behalf of the ESMO Guidelines Working Group: Bladder cancer: ESMO Practice Guidelines for diagnosis, treatment and follow-up. Ann Oncol 25: iii40-iii48, 2014.

2. Parker C, Gillessen S, Heidenreich A and Horwich A: Cancer of the prostate: ESMO Clinical Practice Guidelines for diagnosis, treatment and follow-up. Ann Oncol 26: v69-v77, 2015.

3. Marth C, Landoni F, Mahner S, McCormack M, Gonzalez-Martin A and Colombo N: Cervical cancer: ESMO Clinical Practice Guidelines for diagnosis, treatment and follow-up. Ann Oncol 28 (suppl-4): iv72-iv83, 2017.

4. Colombo N, Preti E, Landoni F, Carinelli S, Colombo A, Marini C and Sessa C; ESMO Guidelines Working Group: Endometrial cancer: ESMO Clinical Practice Guidelines for diagnosis, treatment and follow-up. Ann Oncol 24 (Suppl 6): vi33-vi38, 2013.

5. Ray-Coquard I, Morice P, Lorusso D, Prat J, Oaknin A, Pautier P and Colombo N; ESMO Guidelines Committee: Non-epithelial ovarian cancer: ESMO Clinical Practice Guidelines for diagnosis, treatment and follow-up. Ann Oncol 29 (Suppl 4): iv1-iv18, 2018.

6. Escudier B, Porta C, Schmidinger M, Rioux-Leclercq N, Bex A, Khoo V, Grünwald V, Gillessen S, Horwich A; ESMO Guidelines Committee, et al: Renal cell carcinoma: ESMO Clinical Practice Guidelines for diagnosis, treatment and follow-up. Ann Oncol 30: 706-720, 2019.

7. Colombo N, Sessa C, du Bois A, Ledermann J, McCluggage WG, McNeish I, Morice P, Pignata S, Ray-Coquard I, Vergote I, et al: ESMO-ESGO consensus conference recommendations on ovarian cancer: Pathology and molecular biology, early and advanced stages, borderline tumours and recurrent disease. Ann Oncol 30: 672-705, 2019.

8. Ferlay J, Colombet M, Soerjomataram I, Mathers C, Parkin DM, Piñeros M, Znaor A and Bray F: Estimating the global cancer incidence and mortality in 2018: GLOBOCAN sources and methods. Int J Cancer 144: 1941-1953, 2019

9. Bankhead CR, Kehoe ST and Austoker J: Symptoms associated with diagnosis of ovarian cancer: A systematic review. BJOG 112: 857-865, 2005.

10. Hsieh JJ, Purdue MP, Signoretti S, Swanton C, Albiges L, Schmidinger M, Heng DY, Larkin J and Ficarra V: Renal cell carcinoma. Nat Rev Dis Primers 3: 17009, 2017.

11. Nüsslein-Volhard $C$ and Wieschaus E: Mutations affecting segment number and polarity in Drosophila. Nature 287: 795-801, 1980.

12. Rivell A, Petralia RS, Wang YX, Clawson E, Moehl K, Mattson MP and Yao PJ: Sonic hedgehog expression in the postnatal brain. Biology Open 8: bio040592, 2019.

13. Fattahi S, Pilehchian Langroudi $M$ and Akhavan-Niaki $H$ : Hedgehog signaling pathway: Epigenetic regulation and role in disease and cancer development. J Cell Physiol 233: 5726-5735, 2018.

14. Wang C, Cassandras M and Peng T: The Role of hedgehog signaling in adult lung regeneration and maintenance. J Dev Biol 7: 14, 2019.

15. Skoda AM, Simovic D, Karin V, Kardum V, Vranic S and Serman L: The role of the Hedgehog signaling pathway in cancer: A comprehensive review. Bosn J of Basic Med Sci 18: 8-20, 2018.

16. Cohen M, Kicheva A, Ribeiro A, Blassberg R, Page KM, Barnes CP and Briscoe J: Ptch1 and Gli regulate Shh signalling dynamics via multiple mechanisms. Nat Commun 6: 6709, 2015.

17. Katoh M: Genomic testing, tumor microenvironment and targeted therapy of Hedgehog-related human cancers. Clin Sci 133: 953-970, 2019.

18. Girardi D, Barrichello A, Fernandes G and Pereira A: Targeting the hedgehog pathway in cancer: Current evidence and future perspectives. Cells 8: 153, 2019.

19. Hua K and Ferland RJ: Primary cilia proteins: Ciliary and extraciliary sites and functions. Cell Mol Life Sci 75: 1521-1540, 2018. 
20. Carballo GB, Honorato JR, de Lopes GPF and Spohr TCL DESE: A highlight on Sonic hedgehog pathway. Cell Commun Signal 16: $11,2018$.

21. Didiasova M, Schaefer L and Wygrecka M: Targeting GLI transcription factors in cancer. Molecules 23: 1003, 2018.

22. ten Haaf A, Bektas N, von Serenyi S, Losen I, Arweiler EC, Hartmann A, Knüchel R and Dahl E: Expression of the glioma-associated oncogene homolog (GLI) lin human breast cancer is associated with unfavourable overall survival. BMC Cancer 9: 298, 2009.

23. Im S, Choi HJ, Yoo C, Jung JH, Jeon YW, Suh YJ and Kang CS Hedgehog related protein expression in breast cancer: Gli-2 is associated with poor overall survival. Korean J Pathol 47: 116-123, 2013.

24. Choe JY, Yun JY, Jeon YK, Kim SH, Choung HK, Oh S, Park M and Kim JE: Sonic hedgehog signalling proteins are frequently expressed in retinoblastoma and are associated with aggressive clinicopathological features. J Clin Pathol 68: 6-11, 2015.

25. Al Ghamdi D, Gomaa W, Abulaban A, Al-Ahwal M, Buhmeida A Al-Qahtani M and Al-Maghrabi J: The significance of sonic hedgehog immunohistochemical expression in colorectal carcinoma. J Microsc Ultrastruct 3: 169-174, 2015.

26. Bai XY, Lin JY, Zhang XC, Xie Z, Yan HH, Chen ZH, Xu CR, An SJ, Sheng GM and Wu YL: High expression of truncated GLI3 is associated with poor overall survival in patients with non-small cell lung cancer. Cancer Biomark 13: 37-47, 2013.

27. Ding YL, Wang QS, Zhao WM and Xiang L: Expression of smoothened protein in colon cancer and its prognostic value for postoperative liver metastasis. Asian Pac J Cancer Prev 13: 4001-4005, 2012.

28. Aberger F and Frischauf AM: GLI Genes and Their Targets in Epidermal Development and Disease. Landes Bioscience, 2013.

29. Lesiak A, Sobolewska-Sztychny D, Danilewicz M, Rogowski-Tylman M, Sysa-Jedrzejowska A, Sobjanek M, Olejniczak-Staruch I and Narbutt J: Sonic hedgehog pathway dysregulation in skin basal-cell carcinoma of a Polish population. Folia Histochem Cytobiol 51: 219-224, 2013.

30. Liu F, Jiang W, Sui Y, Meng W, Hou L, Li T, Li M, Zhang L, Mo J, Wang J, et al: CDK7 inhibition suppresses aberrant hedgehog pathway and overcomes resistance to smoothened antagonists. Proc Natl Acad Sci USA 116: 12986-12995, 2019.

31. Fernandes-Silva H, Correia-Pinto J and Moura RS: Canonical sonic hedgehog signaling in early lung development. J Dev Biol 5: 3, 2017.

32. Memi F, Zecevic N and Radonjić N: Multiple roles of Sonic Hedgehog in the developing human cortex are suggested by its widespread distribution. Brain Struct Funct 223: 2361-2375, 2018 .

33. Odent S, Attie-Bitach T, Blayau M, Mathieu M, Aug J, Delezo de AL, Gall JY, Le Marec B, Munnich A, David V and Vekemans M: Expression of the Sonic hedgehog (SHH) gene during early human development and phenotypic expression of new mutations causing holoprosencephaly. Hum Mol Genet 8 : $1683-1689,1999$.

34. Kim A, Le Douce J, Diab F, Ferovova M, Dubourg C, Odent S, Dupé V, David V, Diambra L, Watrin E and de Tayrac M: Synonymous variants in holoprosencephaly alter codon usage and impact the Sonic Hedgehog protein. Brain 143: 2027-2038, 2020.

35. Fabik J, Kovacova K, Kozmik Z and Machon O: Neural crest cells require Meis2 for patterning the mandibular arch via the Sonic hedgehog pathway. Biol Open 9: bio052043, 2020.

36. Bürglin TR: The Hedgehog protein family. Genome Biol 9: 241, 2008.

37. Hanna A and Shevde LA: Hedgehog signaling: Modulation of cancer properies and tumor mircroenvironment. Mol Cancer 15: $24,2016$.

38. Nikolopoulou E, Galea GL, Rolo A, Greene NDE and Copp AJ: Neural tube closure: Cellular, molecular and biomechanical mechanisms. Development 144: 552-566, 2017.

39. Roessler E, Belloni E, Gaudenz K, Vargas F, Scherer SW, Tsui LC and Muenke M: Mutations in the C-terminal domain of sonic hedgehog cause holoprosencephaly. Hum Mol Genet 6 : 1847-1853, 1997.

40. Mimeault $M$ and Batra SK: Frequent deregulations in the hedgehog signaling network and cross-talks with the epidermal growth factor receptor pathway involved in cancer progression and targeted therapies. Pharmacol Rev 62: 497-524, 2010.

41. Varjosalo $M$ and Taipale J: Hedgehog: Functions and mechanisms. Genes Dev 22: 2454-2472,2008.
42. Chamoun Z, Mann RK, Nellen D, von Kessler DP, Bellotto M, Beachy PA and Basler K: Skinny hedgehog, an acyltransferase required for palmitoylation and activity of the hedgehog signal. Science 293: 2080-2084, 2001

43. Lanyon-Hogg T, Masumoto N, Bodakh G, Konitsiotis AD Thinon E, Rodgers UR, Owens RJ, Magee AI and Tate EW: Synthesis and characterisation of 5-acyl-6,7-dihydrothieno[3,2-c] pyridine inhibitors of Hedgehog acyltransferase. Data Brief 7: 257-281, 2016.

44. Rodgers UR, Lanyon-Hogg T, Masumoto N, Ritzefeld M, Burke R, Blagg J, Magee AI and Tate EW: Characterization of hedgehog acyltransferase inhibitors identifies a small molecule probe for hedgehog signaling by cancer cells. ACS Chem Biol 11: $3256-3262,2016$

45. Gong X, Qian H, Cao P, Zhao X, Zhou Q, Lei J and Yan N: Structural basis for the recognition of Sonic Hedgehog by human Patched1. Science 361: eaas8935, 2018.

46. Choudhry Z, Rikani AA, Choudhry AM, Tariq S, Zakaria F, Asghar MW, Sarfraz MK, Haider K, Shafiq AA and Mobassarah NJ: Sonic hedgehog signalling pathway: A complex network. Ann Neurosci 21: 28-31, 2014

47. Bausch D, Fritz S, Bolm L, Wellner UF, Fernandez-Del-Castillo C, Warshaw AL, Thayer SP and Liss AS: Hedgehog signaling promotes angiogenesis directly and indirectly in pancreatic cancer. Angiogenesis 23: 479-492, 2020.

48. Qi X, Schmiege P, Coutavas E, Wang J and Li X: Structures of human Patched and its complex with native palmitoylated sonic hedgehog. Nature 560: 128-132, 2018.

49. Martinez MF, Romano MV, Martinez AP, González A, Muchnik C, Stengel FM, Mazzuoccolo LD and Azurmendi PJ: Nevoid Basal Cell Carcinoma Syndrome: PTCH1 mutation profile and expression of genes involved in the hedgehog pathway in argentinian patients. Cells 8: 144, 2019.

50. Fleet AJ and Hamel PA: The protein-specific activities of the transmembrane modules of Ptch1 and Ptch 2 are determined by their adjacent protein domains. J Biol Chem 293: 16583-16595, 2018.

51. Holtz AM, Peterson KA, Nishi Y, Morin S, Song JY, Charron F, McMahon AP and Allen BL: Essential role for ligand-dependent feedback antagonism of vertebrate hedgehog signaling by PTCH1, PTCH2 and HHIP1 during neural patterning. Development 140: 3423-3434, 2013

52. Kowatsch C, Woolley RE, Kinnebrew M, Rohatgi R and Siebold C: Structures of vertebrate Patched and Smoothened reveal intimate links between cholesterol and Hedgehog signalling. Curr Opin Struct Biol 57: 204-214, 2019.

53. Xiao X, Tang JJ, Peng C, Wang Y, Fu L, Qiu ZP, Xiong Y, Yang LF, Cui HW, He XL, et al: Cholesterol modification of smoothened is required for hedgehog signaling. Mol Cell 66: 154-162.e10, 2017

54. Denef N, Neubüser D, Perez L and Cohen SM: Hedgehog induces opposite changes in turnover and subcellular localization of patched and smoothened. Cell 102: 521-531, 2000.

55. Jiang K and Jia J: Smoothened regulation in response to Hedgehog stimulation. Front Biol 10: 475-486, 2015

56. Huang P, Zheng S, Wierbowski BM, Kim Y, Nedelcu D, Aravena L, Liu J, Kruse AC and Salic A: Structural basis of smoothened activation in hedgehog signaling. Cell 174: 312-324. e16, 2018

57. Qi Y, Liu H and Lin X: Sumoylation stabilizes smoothened to promote hedgehog signaling. Dev Cell 39: 385-387, 2016

58. Zhang B, Zhuang T, Lin Q, Yang B, Xu X, Xin G, Zhu S, Wang G, Yu B, Zhang T, et al: Patched1-ArhGAP36-PKA-Inversin axis determines the ciliary translocation of Smoothened for Sonic Hedgehog pathway activation. Proc Natl Acad Sci USA 116: 874-879, 2019.

59. Rohatgi R and Scott MP: Cell biology. Arrestin' movement in cilia. Science 320: 1726-1727, 2008.

60. Cochrane CR, Szczepny A, Watkins DN and Cain JE: Hedgehog signaling in the maintenance of cancer stem cells. Cancers (Basel) 7: 1554-1585, 2015.

61. Carpenter RL and Ray H: Safety and tolerability of sonic hedgehog pathway inhibitors in cancer. Drug Saf 42: 263-279, 2019.

62. Hoy SM: Glasdegib: First Global Approval. Drugs 79: 207-213, 2019.

63. Pietrobono S, Gagliardi S and Stecca B: Non-canonical hedgehog signaling pathway in cancer: Activation of GLI transcription factors beyond smoothened. Front Genet 10: 556, 2019. 
64. Peer E, Tesanovic S and Aberger F: Next-generation hedgehog/GLI pathway inhibitors for cancer therapy. Cancers 11: $538,2019$.

65. Sabol M, Trnski D, Musani V, Ozretić P and Levanat S: Role of GLI Transcription factors in pathogenesis and their potential as new therapeutic targets. Int J Mol Sci 19: 2562, 2018.

66. Ruppert JM, Kinzler KW, Wong AJ, Bigner SH, Kao FT, Law ML, Seuanez HN, O'Brien SJ and Vogelstein B: The GLI-Kruppel family of human genes. Mol Cell Biol 8: 3104-3113, 1988.

67. Carpenter RL and Lo HW: Hedgehog Pathway and GLI1 Isoforms in Human Cancer. Discov Med 13: 105-113, 2013.

68. Cao X, Geradts J, Dewhirst MW and Lo HW: Upregulation of VEGF-A and CD24 gene expression by the tGLI1 transcription factor contributes to the aggressive behavior of breast cancer cells. Oncogene 31: 104-115, 2012.

69. Carpenter RL and Lo HW: Identification, Functional Characterization, and Pathobiological Significance of GLI1 Isoforms in Human Cancers. In: Vitamins, Hormones. Vol 88 Elsevier, pp115-140, 2012.

70. Niewiadomski P, Niedziółka SM, Markiewicz Ł, Uśpieński T, Baran B and Chojnowska K: Gli Proteins: Regulation in development and cancer. Cells 8: 147, 2019.

71. Pal K, Hwang SH, Somatilaka B, Badgandi H, Jackson PK, DeFea K and Mukhopadhyay S: Smoothened determines $\beta$-arrestin-mediated removal of the $\mathrm{G}$ protein-coupled receptor Gpr161 from the primary cilium. J Cell Biol 212: 861-875, 2016.

72. Briscoe J and Thérond PP: The mechanisms of Hedgehog signalling and its roles in development and disease. Nat Rev Mol Cell Biol 14: 416-429, 2013.

73. Montagnani V and Stecca B: Role of protein kinases in hedgehog pathway control and implications for cancer therapy. Cancers 11: 449, 2019.

74. Mirza AN, McKellar SA, Urman NM, Brown AS, Hollmig T, Aasi SZ and Oro AE: LAP2 proteins chaperone GLI1 movement between the lamina and chromatin to regulate transcription. Cell 176: 198-212.e15, 2019.

75. Canettieri G, Di Marcotullio L, Greco A, Coni S, Antonucci L, Infante P, Pietrosanti L, De Smaele E, Ferretti E, Miele E, et al: Histone deacetylase and Cullin3-REN(KCTD11) ubiquitin ligase interplay regulates Hedgehog signalling through Gli acetylation. Nat Cell Biol 12: 132-142, 2010.

76. Bangs F and Anderson KV: Primary cilia and mammalian hedgehog signaling. Cold Spring Harb Perspect Biol 9: a028175 2017.

77. Wong SY, Seol AD, So PL, Ermilov AN, Bichakjian CK, Epstein EH Jr, Dlugosz AA and Reiter JF: Primary cilia can both mediate and suppress Hedgehog pathway-dependent tumorigenesis. Nat Med 15: 1055-1061, 2009.

78. Han YG, Kim HJ, Dlugosz AA, Ellison DW and Alvarez-Buylla A Dual and opposing roles of primary cilia in medulloblastoma development. Nat Med 15: 1062-10652010.

79. Quaglio D, Infante P, Di Marcotullio L, Botta B and Mori M: Hedgehog signaling pathway inhibitors: An updated patent review (2015-present). Expert Opin Ther Pat 30: 235-250, 2020.

80. Perea SE, Baladrón I, Valenzuela C and Perera Y: CIGB-300: A peptide-based drug that impairs the Protein Kinase CK2-mediated phosphorylation. Semin Oncol 45: 58-67, 2018.

81. Huang S and Houghton PJ: Targeting mTOR signaling for cancer therapy. Curr Opin Pharmacol 3: 371-377, 2003.

82. Sullivan RJ, Infante JR, Janku F, Wong DJL, Sosman JA, Keedy V, Patel MR, Shapiro GI, Mier JW, Tolcher AW, et al: First-in-Class ERK1/2 Inhibitor Ulixertinib (BVD-523) in Patients with MAPK mutant advanced solid tumors: Results of a phase i dose-escalation and expansion study. Cancer Discov 8: 184-195, 2018

83. Xing Y, Lin NU, Maurer MA, Chen H, Mahvash A, Sahin A, Akcakanat A, Li Y, Abramson V, Litton J, et al: Phase II trial of AKT inhibitor MK-2206 in patients with advanced breast cancer who have tumors with PIK3CA or AKT mutations, and/or PTEN loss/PTEN mutation. Breast Cancer Res 21: 78, 2019.

84. Chen H, Shen J, Choy E, Hornicek FJ, Shan A and Duan Z: Targeting DYRK1B suppresses the proliferation and migration of liposarcoma cells. Oncotarget 9: 13154-13166, 2017.

85. Piirsoo A, Kasak L, Kauts ML, Loog M, Tints K, Uusen P, Neuman $T$ and Piirsoo M: Protein kinase inhibitor SU6668 attenuates positive regulation of Gli proteins in cancer and multipotent progenitor cells. Biochim Biophys Acta 1843: 703-714, 2014.

86. Schachter KA and Krauss RS: Murine models of holoprosencephaly. Curr Top Dev Biol 84: 139-170, 2008.
87. Barratt KS and Arkell RM: ZIC2 in Holoprosencephaly. In: Zic family: Evolution, Development and Disease. Aruga J (ed.) Springer, Singapore, pp269-299, 2018.

88. Chen X, Yang S, Zeng J and Chen M: miR-1271-5p inhibits cell proliferation and induces apoptosis in acute myeloid leukemia by targeting ZIC2. Mol Med Rep 19: 508-514, 2019.

89. Li Q, Shi J and Xu X: MicroRNA-1271-5p inhibits the tumorigenesis of ovarian cancer through targeting E2F5 and negatively regulates the mTOR signaling pathway. Panminerva Med, May 14, 2020 (Online ahead of print).

90. Li X, Liu H, Lv Y, Yu W, Liu X and Liu C: MiR-130a-5p/Foxa2 axis modulates fetal lung development in congenital diaphragmatic hernia by activating the Shh/Glil signaling pathway. Life Sci 241: 117166, 2020.

91. Xian X, Tang L, Wu C and Huang L: miR-23b-3p and miR-130a-5p affect cell growth, migration and invasion by targeting $C B 1 R$ via the Wnt $/ \beta$-catenin signaling pathway in gastric carcinoma. Onco Targets Ther 11: 7503-7512, 2018.

92. Huang JL, Fu YP, Gan W, Liu G, Zhou PY, Zhou C, Sun BY, Guan RY, Zhou J, Fan J, et al: Hepatic stellate cells promote the progression of hepatocellular carcinoma through

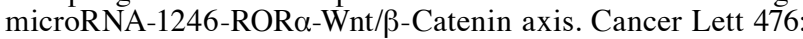
140-151, 2020.

93. Yu Y, Yu F and Sun P: MicroRNA-1246 promotes melanoma progression through targeting FOXA2. Onco Targets Ther 13: 1245-1253, 2020.

94. Jeong JH, Park SJ, Dickinson SI and Luo JL: A constitutive intrinsic inflammatory signaling circuit composed of miR-196b, Meis2, PPP3CC, and p65 drives prostate cancer castration resistance. Mol Cell 65: 154-167, 2017.

95. Guan L, Li T, Ai N, Wang W, He B, Bai Y, Yu Z, Li M, Dong S, Zhu Q, et al: MEIS2C and MEIS2D promote tumor progression via Wnt/ $\beta$-catenin and hippo/YAP signaling in hepatocellular carcinoma. J Exp Clin Cancer Res 38: 417, 2019

96. Richbourg HA, Hu DP, Xu Y, Barczak AJ and Marcucio RS miR-199 family contributes to regulation of sonic hedgehog expression during craniofacial development. Dev Dyn 249: 1062-1076, 2020.

97. Ozretić P, Trnski D, Musani V, Maurac I, Kalafatić D, Orešković S, Levanat S and Sabol M: Non-canonical Hedgehog signaling activation in ovarian borderline tumors and ovarian carcinomas. Int J Oncol 51: 1869-1877, 2017.

98. Mishra P, Panda A, Bandyopadhyay A, Kumar H and Mohiddin G: Sonic hedgehog signalling pathway and ameloblastoma-a review. J Clin Diagn Res 9: ZE10-ZE13, 2015.

99. Bhuria V, Xing J, Scholta T, Bui KC, Nguyen MLT, Malek NP, Bozko P and Plentz RR: Hypoxia induced Sonic Hedgehog signaling regulates cancer stemness, epithelial-to-mesenchymal transition and invasion in cholangiocarcinoma. Exp Cell Res 385: 111671, 2019.

100. Lei J, Fan L, Wei G, Chen X, Duan W, Xu Q, Sheng W, Wang K and $\mathrm{Li} \mathrm{X}$ : Gli-1 is crucial for hypoxia-induced epithelialmesenchymal transition and invasion of breast cancer. Tumour Biol 36: 3119-3126, 2015

101. Seto M, Ohta M, Asaoka Y, Ikenoue T, Tada M, Miyabayashi K, Mohri D, Tanaka Y, Ijichi H, Tateishi K, et al: Regulation of the hedgehog signaling by the mitogen-activated protein kinase cascade in gastric cancer. Mol Carcinog 48: 703-712, 2009.

102. Stecca B, Mas C, Clement V, Zbinden M, Correa R, Piguet V, Beermann F, Ruiz I and Altaba A: Melanomas require HEDGEHOG-GLI signaling regulated by interactions between GLI1 and the RAS-MEK/AKT pathways. Proc Natl Acad Sci USA 104: 5895-5900, 2007.

103. Singh R, Dhanyamraju PK and Lauth M: DYRK1B blocks canonical and promotes non-canonical Hedgehog signaling through activation of the mTOR/AKT pathway. Oncotarget 8 : 833-845, 2017

104. Stemmer V, de Craene B, Berx G and Behrens J: Snail promotes Wnt target gene expression and interacts with beta-catenin. Oncogene 27: 5075-5080, 2008.

105. Rishikaysh P, Dev K, Diaz D, Qureshi WMS, Filip S and Mokry J: Signaling involved in hair follicle morphogenesis and development. Int J Mol Sci 15: 1647-1670, 2014

106. Qi Y, Zhao W, Wang Z, Xie Q, Cao J and Meng X: Cross regulation of signaling pathways in gastrointestinal stromal tumor. Oncol Lett 16: 6770-6776, 2018.

107. Yoon JW, Gallant M, Lamm ML, Iannaccone S, Vieux KF, Proytcheva M, Hyjek E, Iannaccone P and Walterhouse D: Noncanonical regulation of the hedgehog mediator GLI1 by c-MYC in burkitt lymphoma. Mol Cancer Res 11: 604-615, 2013. 
108. Whitson RJ, Lee A, Urman NM, Mirza A, Yao CY, Brown AS Li JR, Shankar G, Fry MA, Atwood SX, et al: Noncanonical hedgehog pathway activation through SRF-MKL1 promotes drug resistance in basal cell carcinomas. Nat Med 24: 271-281, 2018.

109. Liang R, Kagwiria R, Zehender A, Dees C, Bergmann C, Ramming A, Krasowska D, Michalska-Jakubus M, Kreuter A, Kraner ME, et al: Acyltransferase skinny hedgehog regulates TGF $\beta$-dependent fibroblast activation in SSc. Ann Rheum Dis 78: 1269-1273, 2019.

110. Yang H, Hu L, Liu Z, Qin Y, Li R, Zhang G, Zhao B, Bi C, Lei Y and Bai Y: Inhibition of Gli1-mediated prostate cancer cell proliferation by inhibiting the mTOR/S6K1 signaling pathway. Oncol Lett 14: 7970-7976, 2017.

111. Robbins DJ, Fei DL and Riobo NA: The hedgehog signal transduction network. Sci Signal 5: re6, 2012.

112. Barnes EA, Kong M, Ollendorff V and Donoghue D: Patched1 interacts with cyclin B1 to regulate cell cycle progression. EMBO J 20: 2214-2223, 2001

113. Barnes EA, Heidtman KJ and Donoghue DJ: Constitutive activation of the shh-ptc1 pathway by a patched 1 mutation identified in BCC. Oncogene 24: 902-915, 2005.

114. Thibert C: Inhibition of neuroepithelial patched-induced apoptosis by sonic hedgehog. Science 301: 843-846, 2003

115. Mille F, Thibert C, Fombonne J, Rama N, Guix C, Hayashi H, Corset V, Reed JC and Mehlen P: The Patched dependence receptor triggers apoptosis through a DRAL-caspase-9 complex. Nat Cell Biol 11: 739-746, 2009.

116. Sasaki N, Kurisu J and Kengaku M: Sonic hedgehog signaling regulates actin cytoskeleton via Tiam1-Racl cascade during spine formation. Mol Cell Neurosci 45: 335-344, 2010.

117. Chinchilla P, Xiao L, Kazanietz MG and Riobo NA: Hedgehog proteins activate pro-angiogenic responses in endothelial cells through non-canonical signaling pathways. Cell Cycle 9 : $570-579,2010$

118. Polizio AH, Chinchilla P, Chen X, Kim S, Manning DR and Riobo NA: Heterotrimeric $G_{i}$ proteins link hedgehog signaling to activation of rho small GTPases to promote fibroblast migration. J Biol Chem 286: 19589-19596, 2011.

119. Belgacem YH and Borodinsky LN: Sonic hedgehog signaling is decoded by calcium spike activity in the developing spinal cord. Proc Natl Acad Sci USA 108: 4482-4487, 2011.

120. Gupta S, Takebe N and LoRusso P: Targeting the Hedgehog pathway in cancer. Ther Adv Med Oncol 2: 237-250, 2010.

121. Reifenberger J, Wolter M, Knobbe CB, Köhler B, Schönicke A, Scharwächter C, Kumar K, Blaschke B, Ruzicka T and Reifenberger G: Somatic mutations in the PTCH, SMOH, SUFUH and TP53 genes in sporadic basal cell carcinomas. Br J Dermatol 152: 43-51, 2005.

122. Cheng WT, Xu K, Tian DY, Zhang ZG, Liu LJ and Chen Y: Role of Hedgehog signaling pathway in proliferation and invasiveness of hepatocellular carcinoma cells. Int J Oncol 34: 829-836, 2009.

123. Tian H, Callahan CA, DuPree KJ, Darbonne WC, Ahn CP, Scales SJ and de Sauvage FJ: Hedgehog signaling is restricted to the stromal compartment during pancreatic carcinogenesis. Proc Natl Acad Sci USA 106: 4254-4259, 2009

124. Yauch RL, Gould SE, Scales SJ, Tang T, Tian H, Ahn CP, Marshall D, Fu L, Januario T, Kallop D, et al: A paracrine requirement for hedgehog signalling in cancer. Nature 455 406-410, 2008

125. Jeng KS, Chang CF and Lin SS: Sonic hedgehog signaling in organogenesis, tumors, and tumor microenvironments. Int J Mol Sci 21: 758, 2020

126. Santi A, Kugeratski FG and Zanivan S: Cancer Associated Fibroblasts: The Architects of Stroma Remodeling. Proteomics 18: e1700167, 2018.

127. Valenti G, Quinn HM, Heynen GJJE, Lan L, Holland JD, Vogel R, Wulf-Goldenberg A and Birchmeier W: Cancer stem cells regulate cancer-associated fibroblasts via activation of hedgehog signaling in mammary gland tumors. Cancer Res 77 2134-2147, 2017.

128. von Ahrens D, Bhagat TD, Nagrath D, Maitra A and Verma A The role of stromal cancer-associated fibroblasts in pancreatic cancer. J Hematol Oncol 10: 76, 2017.

129. Petty AJ, Li A, Wang X, Dai R, Heyman B, Hsu D, Huang X and Yang Y: Hedgehog signaling promotes tumor-associated macrophage polarization to suppress intratumoral CD8+ T cell recruitment. J Clin Invest 129: 5151-5162, 2019.
130. Fan Q, He M, Sheng T, Zhang X, Sinha M, Luxon B, Zhao X and Xie J: Requirement of TGFbeta Signaling for SMO-mediated carcinogenesis. J Biol Chem 285: 36570-36576, 2010.

131. Maximov V, Chen Z, Wei Y, Robinson MH, Herting CJ, Shanmugam NS, Rudneva VA, Goldsmith KC, MacDonald TJ, Northcott PA, et al: Tumour-associated macrophages exhibit anti-tumoural properties in Sonic Hedgehog medulloblastoma. Nat Commun 10: 2410, 2019

132. Moch H, Cubilla AL, Humphrey PA, Reuter VE and Ulbright TM: The 2016 WHO classification of tumours of the urinary system and male genital organs-part a: Renal, penile, and testicular tumours. Eur Urol 70: 93-105, 2016.

133. Cheville JC, Lohse CM, Zincke H, Weaver AL and Blute ML: Comparisons of outcome and prognostic features among histologic subtypes of renal cell carcinoma. Am J Surg Pathol 27 612-624, 2003

134. Sanchez DJ and Simon MC: Genetic and metabolic hallmarks of clear cell renal cell carcinoma. Biochim Biophys Acta Rev Cancer 1870: 23-31, 2018.

135. Brugarolas J: Molecular genetics of clear-cell renal cell carcinoma. J Clin Oncol 32: 1968-1976, 2014

136. Gossage L, Eisen T and Maher ER: VHL, the story of a tumour suppressor gene. Nat Rev Cancer 15: 55-64, 2015.

137. Le Tourneau C, Raymond E and Faivre S: Sunitinib: A novel tyrosine kinase inhibitor. A brief review of its therapeutic potential in the treatment of renal carcinoma and gastrointestinal stromal tumors (GIST). Ther Clin Risk Manag 3: 341-348, 2007.

138. Dormoy V, Danilin S, Lindner V, Thomas L, Rothhut S, Coquard C, Helwig JJ, Jacqmin D, Lang H and Massfelder T: The sonic hedgehog signaling pathway is reactivated in human renal cell carcinoma and plays orchestral role in tumor growth. Mol Cancer 8: 123, 2009.

139. Samaratunga $H$, Gianduzzo $T$ and Delahunt B: The ISUP system of staging, grading and classification of renal cell neoplasia. J Kidney Cancer VHL 1: 26-39, 2014.

140. Jäger W, Thomas C, Fazli L, Hurtado-Coll A, Li E, Janssen C, Gust KM, So AI, Hainz M, Schmidtmann I, et al: DHH is an independent prognosticator of oncologic outcome of clear cell renal cell carcinoma. J Urol 192: 1842-1848, 2014

141. Furukawa J, Miyake H and Fujisawa M: GLI2 expression levels in radical nephrectomy specimens as a predictor of disease progression in patients with metastatic clear cell renal cell carcinoma following treatment with sunitinib. Mol Clin Oncol 5: 186-192, 2016

142. Behnsawy HM, Shigemura K, Meligy FY, Yamamichi F, Yamashita M, Haung WC, Li X, Miyake H, Tanaka K, Kawabata M, et al: Possible role of sonic hedgehog and epithelial-mesenchymal transition in renal cell cancer progression. Korean J Urol 54: 547-554, 2013.

143. Kotulak-Chrzaszcz A, Klacz J, Matuszewski M, Kmiec Z and Wierzbicki P: Expression of the Sonic Hedgehog pathway components in clear cell renal cell carcinoma. Oncol Lett 18: 5801-5810, 2019

144. Shang Z, Zhao T, Ou T, Yan H, Cui B, Wang Q, Wu J, Jia C, Cui $\mathrm{X}$ and $\mathrm{Li} \mathrm{J}$ : The level of zinc finger of the cerebellum 2 is predictive of overall survival in clear cell renal cell carcinoma. Transl Androl Urol 9: 614-620, 2020.

145. Jia Z, Wan F, Zhu Y, Shi G, Zhang H, Dai B and Ye D: Forkhead-box series expression network is associated with outcome of clear-cell renal cell carcinoma. Oncol Lett 15: 8669-8680, 2018.

146. Zhou J, Wu K, Gao D, Zhu G, Wu D, Wang X, Chen Y, Du Y, Song W, Ma Z, et al: Reciprocal regulation of hypoxia-inducible factor $2 \alpha$ and GLI1 expression associated with the radioresistance of renal cell carcinoma. Int J Radiat Oncol Biol Phys 90: 942-951, 2014

147. Zhou J, Zhu G, Huang J, Li L, Du Y, Gao Y, Wu D, Wang X, Hsieh JT, He D and Wu K: Non-canonical GLI1/2 activation by PI3K/AKT signaling in renal cell carcinoma: A novel potential therapeutic target. Cancer Lett 370: 313-323, 2016.

148. D'Amato C, Rosa R, Marciano R, D'Amato V, Formisano L, Nappi L, Raimondo L, Di Mauro C, Servetto A, Fulciniti F, et al: Inhibition of hedgehog signalling by NVP-LDE225 (Erismodegib) interferes with growth and invasion of human renal cell carcinoma cells. Br J Cancer 111: 1168-1179, 2014.

149. Bray F, Ferlay J, Soerjomataram I, Siegel RL, Torre LA and Jemal A: Global cancer statistics 2018: GLOBOCAN estimates of incidence and mortality worldwide for 36 cancers in 185 countries. CA Cancer J Clin 68: 394-424, 2018 
150. Zhang X and Zhang Y: Bladder cancer and genetic mutations. Cell Biochem Biophys 73: 65-69, 2015.

151. Mobley D and Baum N: Smoking: Its impact on urologic health Rev Urol 17: 220-225, 2015.

152. Jalanko T, de Jong JJ, Gibb EA, Seiler R and Black PC: Genomic subtyping in bladder cancer. Curr Urol Rep 21: 9, 2020.

153. He HC, Chen JH, Chen XB, Qin GQ, Cai C, Liang YX, Han ZD, Dai QS, Chen YR, Zeng GH, et al: Expression of hedgehog pathway components is associated with bladder cancer progression and clinical outcome. Pathol Oncol Res 18: 349-355, 2012.

154. Nedjadi T, Salem N, Khayyat D, Al-Sayyad A, Al-Ammari A and Al-Maghrabi J: Sonic hedgehog expression is associated with lymph node invasion in urothelial bladder cancer. Patho Oncol Res 25: 1067-1073, 2019.

155. Xie R, Chen X, Chen Z, Huang M, Dong W, Gu P, Zhang J, Zhou Q, Dong W, Han J, et al: Polypyrimidine tract binding protein 1 promotes lymphatic metastasis and proliferation of bladder cancer via alternative splicing of MEIS2 and PKM. Cancer Lett 449: 31-44, 2019.

156. Islam SS, Mokhtari RB, Noman AS, Uddin M, Rahman MZ, Azadi MA, Zlotta A, van der Kwast T, Yeger $\mathrm{H}$ and Farhat WA: Sonic hedgehog (Shh) signaling promotes tumorigenicity and stemness via activation of epithelial-to-mesenchymal transition (EMT) in bladder cancer. Mol Carcinog 55: 537-551, 2016.

157. Kitagawa K, Shigemura K, Sung SY, Chen KC, Huang CC, Chiang YT, Liu MC, Huang TW, Yamamichi F, Shirakawa T and Fujisawa M: Possible correlation of sonic hedgehog signaling with epithelial-mesenchymal transition in muscle-invasive bladder cancer progression. J Cancer Res Clin Oncol 145: 2261-2271, 2019.

158. Kim S, Kim Y, Kong J, Kim E, Choi JH, Yuk HD, Lee H, Kim HR, Lee KH, Kang M, et al: Epigenetic regulation of mammalian Hedgehog signaling to the stroma determines the molecular subtype of bladder cancer. Elife 8: e43024, 2019.

159. Amin MB, Edge S, Greene F, Byrd DR, Brookland RK, Washington MK, Gershenwald JE, Compton CC, Hess KR, Sullivan DC, et al (eds): AJCC cancer staging manual. 8th edition. Springer International Publishing, Chicago, IL, 2017.

160. Ho J, Du Y, Wong OG, Siu MK, Chan KK and Cheung AN Downregulation of the gli transcription factors regulator Kif 7 facilitates cell survival and migration of choriocarcinoma cells. PLoS One 9: e108248, 2014

161. Yap J, Fox R, Narsia N, Pinheiro-Maia S, Pounds R, Woodman C, Luesley D, Ganesan R, Kehoe S and Dawson C: Under expression of the Sonic Hedgehog receptor, Patched1 (PTCH1), is associated with an increased risk of local recurrence in squamous cell carcinoma of the vulva arising on a background of Lichen Sclerosus. PLoS One 13: e0206553, 2018.

162. Rosen DG, Yang G, Liu G, Mercado-Uribe I, Chang B, Xiao XS, Zheng J, Xue FX and Liu J: Ovarian cancer: Pathology, biology, and disease models. Front Biosci (Landmark Ed) 14: 2089-2102, 2009.

163. Levanat S, Musani V, Komar A and Orešković S: Role of the Hedgehog/Patched Signaling Pathway in Oncogenesis: A new polymorphism in the PTCH gene in ovarian fibroma. Ann N Y Acad Sci 1030: 134-143, 2004.

164. Marchini S, Poynor E, Barakat RR, Clivio L, Cinquini M, Fruscio R, Porcu L, Bussani C, D'Incalci M, Erba E, et al The zinc finger gene ZIC2 has features of an oncogene and its overexpression correlates strongly with the clinical course of epithelial ovarian cancer. Clin Cancer Res 18: 4313-4324, 2012.

165. Salem M, O'Brien JA, Bernaudo S, Shawer H, Ye G, Brkić J, Amleh A, Vanderhyden BC, Refky B, Yang BB, et al: miR-590-3p Promotes ovarian cancer growth and metastasis via a Novel FOXA2-versican pathway. Cancer Res 78: 4175-4190, 2018

166. Peng Q, Qin J, Zhang Y, Cheng X, Wang X, Lu W, Xie X and Zhang S: Autophagy maintains the stemness of ovarian cancer stem cells by FOXA2. J Exp Clin Cancer Res 36: 171, 2017.

167. Musani V, Sabol M, Car D, Ozretić P, Kalafatić D, Maurac I, Orešković S and Levanat S: PTCH1 gene polymorphisms in ovarian tumors: Potential protective role of c.3944T allele. Gene 517: 55-59, 2013.

168. Cretnik M, Musani V, Oreskovic S, Leovic D and Levanat S: The Patched gene is epigenetically regulated in ovarian dermoids and fibromas, but not in basocellular carcinomas. Int J Mol Med 19: 875-883, 2007.
169. Hainsworth JD, Meric-Bernstam F, Swanton C, Hurwitz H, Spigel DR, Sweeney C, Burris H, Bose R, Yoo B, Stein A, et al: Targeted therapy for advanced solid tumors on the basis of molecular profiles: Results from mypathway, an open-label, phase IIa multiple basket study. J Clin Oncol 36: 536-542, 2018

170. Liao X, Siu MK, Au CW, Wong ES, Chan HY, Ip PP, Ngan HY and Cheung AN: Aberrant activation of hedgehog signaling pathway in ovarian cancers: Effect on prognosis, cell invasion and differentiation. Carcinogenesis 30: 131-140, 2009.

171. Yang L, He J, Huang S, Zhang X, Bian Y, He N, Zhang H and $\mathrm{Xie} \mathrm{J}$ : Activation of hedgehog signaling is not a frequent event in ovarian cancers. Mol Cancer 8: 112, 2009.

172. Schmid S, Bieber M, Zhang F, Zhang M, He B, Jablons D and Teng NN: Wnt and hedgehog gene pathway expression in serous ovarian cancer. Int J Gynecol Cancer 21: 975-980, 2011.

173. Trnski D, Gregorić M, Levanat S, Ozretić P, Rinčić N, Vidaković TM, Kalafatić D, Maurac I, Orešković S, Sabol M and Musani V: Regulation of survivin isoform expression by GLI proteins in ovarian cancer. Cells 8: 128, 2019.

174. Vlčková K, Ondrušová L, Vachtenheim J, Réda J, Dundr P, Zadinová M,Žáková P and Poučková P: Survivin, a novel target of the Hedgehog/GLI signaling pathway in human tumor cells. Cell Death Dis 7: e2048, 2016.

175. Zhang H, Wang Y, Chen T, Zhang Y, Xu R, Wang W, Cheng M and Chen Q: Aberrant activation of hedgehog signalling promotes cell migration and invasion via matrix metalloproteinase-7 in ovarian cancer cells. J Cancer 10: 990-1003, 2019.

176. Xu M, Hu X, Zhang M and Ge Y: What is the impact of BIRC5 gene polymorphisms on urinary cancer susceptibility? Evidence from 9348 subjects. Gene 733: 144268, 2020.

177. Sneha S, Nagare RP, Sidhanth C, Krishnapriya S, Garg M, Ramachandran B, Murhekar K, Sundersingh S and Ganesan TS: The hedgehog pathway regulates cancer stem cells in serous adenocarcinoma of the ovary. Cell Oncol (Dordr) 43: 601-616, 2020.

178. Sun X, Song J, Li E, Geng H, Li Y, Yu D and Zhong C: (-)-Epigallocatechin-3-gallate inhibits bladder cancer stem cells via suppression of sonic hedgehog pathway. Oncol Rep 42: 425-435, 2019

179. Li X, Wang X, Xie C, Zhu J, Meng Y, Chen Y, Li Y, Jiang Y, Yang X, Wang S, et al: Sonic hedgehog and Wnt/ $\beta$-catenin pathways mediate curcumin inhibition of breast cancer stem cells. Anticancer Drugs 29: 208-215, 2018.

180. Rojo-León V, García C, Valencia C, Méndez MA, Wood C and Covarrubias L: The E6/E7 oncogenes of human papilloma virus and estradiol regulate hedgehog signaling activity in a murine model of cervical cancer. Exp Cell Res 381: 311-322, 2019.

181. Chen H, Wang J, Yang H, Chen D and Li P: Association between FOXM1 and hedgehog signaling pathway in human cervical carcinoma by tissue microarray analysis. Oncol Lett 12: 2664-2673, 2016.

182. Vishnoi K, Mahata S, Tyagi A, Pandey A, Verma G, Jadli M, Singh T, Singh SM and Bharti AC: Cross-talk between human papillomavirus oncoproteins and hedgehog signaling synergistically promotes stemness in cervical cancer cells. Sci Rep 6: 34377,2016

183. Wang XH, He X, Jin HY, Liang JX and Li N: Effect of hypoxia on the Twist 1 in EMT of cervical cancer cells. Eur Rev Med Pharmacol Sci 22: 6633-6639, 2018

184. Wang YF, Yang HY, Shi XQ and Wang Y: Upregulation of microRNA-129-5p inhibits cell invasion, migration and tumor angiogenesis by inhibiting ZIC2 via downregulation of the Hedgehog signaling pathway in cervical cancer. Cancer Biol Ther 19: 1162-1173, 2018

185. Pereira J, Johnson WE, O'Brien SJ, Jarvis ED, Zhang G, Gilbert MT, Vasconcelos V and Antunes A: Evolutionary Genomics and Adaptive Evolution of the Hedgehog Gene Family (Shh, Ihh and Dhh) in Vertebrates. PLoS One 9: e74132, 2014.

186. Joodi M, Amerizadeh F, Hassanian SM Erfani M, Ghayour-Mobarhan M, Ferns GA, Khazaei M and Avan A: The genetic factors contributing to hypospadias and their clinical utility in its diagnosis. J Cell Physiol 234: 5519-5523, 2019.

187. Aurilio G, Cimadamore A, Santoni M, Nolè F, Scarpelli M, Massari F, Lopez-Beltran A, Cheng L and Montironi R: New frontiers in prostate cancer treatment: Are we ready for drug combinations with novel agents? Cells 9: 1522, 2020

188. Le V, He Y, Aldahl J, Hooker E, Yu EJ, Olson A, Kim WK, Lee DH, Wong M, Sheng R, et al: Loss of androgen signaling in mesenchymal sonic hedgehog responsive cells diminishes prostate development, growth, and regeneration. PLoS Genet 16: e1008588, 2020 
189. Datta S and Datta MW: Sonic Hedgehog signaling in advanced prostate cancer. Cell Mol Life Sci 63: 435-448, 2006.

190. Yamamichi F, Shigemura K, Behnsawy HM, Meligy FY, Huang WC, Li X, Yamanaka K, Hanioka K, Miyake H, Tanaka $\mathrm{K}$, et al: Sonic hedgehog and androgen signaling in tumor and stromal compartments drives epithelial-mesenchymal transition in prostate cancer. Scand J Urol 48: 523-532, 2014.

191. Zhang X, Zhang Y, Lin F, Shi X, Xiang L and Li L: Shh overexpression is correlated with GRP78 and AR expression in primary prostate cancer: Clinicopathological features and outcomes in a chinese cohort. Cancer Manag Res 12: 1569-1578, 2020.

192. Tzelepi V, Karlou M, Wen S, Hoang A, Logothetis C, Troncoso P and Efstathiou E: Expression of hedgehog pathway components in prostate carcinoma microenvironment: Shifting the balance towards autocrine signalling: Hedgehog pathway in prostate cancer. Histopathology 58: 1037-1047, 2011.

193. U.S. Natinal Library of Medicine: A Pre-surgical Study of LDE225 in Men With High-risk Localized Prostate Cancer (LDE225). ClinicalTrials.gov Identifier: NCT02111187. https://clinicaltrials.gov/ct2/show/NCT02111187. Last updated March 7, 2019.

194. U.S. Natinal Library of Medicine: A Study of Vismodegib in Men With Metastatic CRPC With Accessible Metastatic Lesions for Tumor Biopsy. ClinicalTrials.gov Identifier: NCT02115828. https://clinicaltrials.gov/ct2/show/results/NCT02115828. Last updated July 20, 2018.

195. Antonarak is ES, Heath EI, Smith DC, Rathkopf D, Blackford AL, Danila DC, King S, Frost A, Ajiboye AS, Zhao M, et al: Repurposing itraconazole as a treatment for advanced prostate cancer: A noncomparative randomized phase II trial in men with metastatic castration-resistant prostate cancer. Oncologist 18: 163-173, 2013.

196. Xie H, Paradise BD, Ma WW and Fernandez-Zapico ME: Recent advances in the clinical targeting of hedgehog/GLI signaling in cancer. Cells 8: 394, 2019.

197. Kim JE, Singh RR, Cho-Vega JH, Drakos E, Davuluri Y, Khokhar FA, Fayad L, Medeiros LJ and Vega F: Sonic hedgehog signaling proteins and ATP-binding cassette G2 are aberrantly expressed in diffuse large B-cell lymphoma. Mod Pathol 22: 1312-1320, 2009.

198. Ciccone V, Morbidelli L, Ziche M and Donnini S: How to conjugate the stemness marker ALDH1A1 with tumor angiogenesis, progression, and drug resistance. Cancer Drug Resist 3: 26-37, 2020.

199. Bigelow RLH, Chari NS, Unden AB, Spurgers KB, Lee S, Roop DR, Toftgard R and McDonnell TJ: Transcriptional regulation of bcl-2 mediated by the sonic hedgehog signaling pathway through gli-1. J Biol Chem 279: 1197-1205, 2004.
200.Li J, Xu J, Cui Y, Wang L, Wang B, Wang Q, Zhang X, Qiu M and Zhang Z: Mesenchymal sufu regulates development of mandibular molars via shh signaling. J Dent Res 98: 1348-1356, 2019.

201. Wang D, Nagle PW, Wang HH, Smit JK, Faber H, Baanstra M, Karrenbeld A, Chiu RK, Plukker JTM and Coppes RP: Hedgehog pathway as a potential intervention target in esophageal cancer. Cancers (Basel) 11: 821, 2019.

202. Cai H, Li H, Li J, Li X, Li Y, Shi Y and Wang D: Sonic hedgehog signaling pathway mediates development of hepatocellular carcinoma. Tumour Biol: Oct 15, 2016 (Epub ahead of print).

203. Park AK, Lee JY, Cheong H, Ramaswamy V, Park SH, Kool M, Phi JH, Choi SA, Cavalli F, Taylor MD and Kim SK: Subgroup-specific prognostic signaling and metabolic pathways in pediatric medulloblastoma. BMC Cancer 19: 571, 2019.

204. Polychronidou G, Kotoula V, Manousou K, Kostopoulos I, Karayannopoulou G, Vrettou E, Bobos M, Raptou G, Efstratiou I, Dionysopoulos D, et al: Mismatch repair deficiency and aberrations in the Notch and Hedgehog pathways are of prognostic value in patients with endometrial cancer. PLoS One 13: e0208221, 2018

205. Katoh Y and Katoh M: Hedgehog target genes: Mechanisms of carcinogenesis induced by aberrant hedgehog signaling activation. Curr Mol Med 9: 873-886, 2009.

206. Jin W, Peng J and Jiang S: The epigenetic regulation of embryonic myogenesis and adult muscle regeneration by histone methylation modification. Biochem Biophys Rep 6: 209-219, 2016.

207. Nasrallah I and Golden JA: Brain, eye, and face defects as a result of ectopic localization of Sonic hedgehog protein in the developing rostral neural tube. Teratology 64: 107-113, 2001.

208. Castillo-Azofeifa D, Seidel K, Gross L, Golden EJ, Jacquez B, Klein OD and Barlow LA: SOX2 regulation by hedgehog signaling controls adult lingual epithelium homeostasis. Development 145: dev164889, 2018

209. Henno P, Grassin-Delyle S, Belle E, Brollo M, Naline E, Sage E, Devillier P and Israël-Biet D: In smokers, Sonic hedgehog modulates pulmonary endothelial function through vascular endothelial growth factor. Respir Res 18: 102, 2017.

This work is licensed under a Creative Commons Attribution-NonCommercial-NoDerivatives 4.0 International (CC BY-NC-ND 4.0) License. 